\title{
Selective excitation in transparent oxyfluoride glass-ceramics doped with $\mathbf{N d}^{3+}$
}

\author{
G. Gorni ${ }^{\mathrm{a}}$, J.J. Velázquez ${ }^{\mathrm{a}}$, G.C. Mather ${ }^{\mathrm{a}}$, A. Durán ${ }^{\mathrm{a}}$, G. Chen ${ }^{\mathrm{b}}$, M. Sundararajan ${ }^{\mathrm{b}}$, R. Balda ${ }^{\mathrm{c}}$, J. Fernández $^{\mathrm{c}}$ \\ and M.J. Pascual ${ }^{\mathrm{a}^{*}}$ \\ ${ }^{a}$ Instituto de Cerámica y Vidrio (CSIC), C/Kelsen 5, 28049 Madrid, Spain. \\ ${ }^{\mathrm{b}}$ Department of Physics and Astronomy, Ohio University, Athens, OH 45701, USA \\ ${ }^{c}$ Applied Physic Department I, Superior school of Engineering, País Vasco University, Bilbao, Spain. \\ Materials Physics Center CSIC-UPV/EHU, San Sebastian, Spain
}

\begin{abstract}
Transparent oxyfluoride nano-glass-ceramics have been prepared by melting-quenching and doped with five different $\mathrm{Nd}^{3+}$ concentrations $(0.1-2 \mathrm{~mol} \%)$ to obtain the most efficient ${ }^{4} \mathrm{~F}_{3 / 2} \rightarrow{ }^{4} \mathrm{I}_{11 / 2,13 / 2}$ emission. It was observed by differential thermal analysis (DTA) that the addition of $\mathrm{Nd}^{3+}$ does not affect the crystallization mechanism which corresponds to a diffusioncontrolled volumetric process that starts from a constant number of nuclei. Nevertheless, the presence of the dopant affects the kinetics due to the progressive increase of $\mathrm{T}_{\mathrm{g}}$ on increasing the $\mathrm{Nd}^{3+}$ content. $\mathrm{LaF}_{3}$ crystals with a size between $9-12 \mathrm{~nm}$ are obtained after heat treatments at $\mathrm{T}_{\mathrm{g}}+20-80{ }^{\circ} \mathrm{C}$ as confirmed by $\mathrm{X}$-ray diffraction (XRD) and high resolution transmission electron microscopy (HR-TEM). Energy dispersive X-ray (EDX) analysis shows the incorporation of $\mathrm{Nd}^{3+}$ ions into the $\mathrm{LaF}_{3}$ nano-crystals. Judd-Ofelt analysis from the absorption spectra further demonstrate the incorporation of $\mathrm{Nd}^{3+}$ ions into the fluoride phase and the most relevant parameters such as radiative lifetime and stimulated emission cross-section are calculated. A detailed optical characterisation clearly shows that $\mathrm{Nd}^{3+}$ ions in the glass-ceramics are incorporated in both crystalline and amorphous phases. Low temperature site-selective emission and excitation spectra, together with the different lifetime values of the ${ }^{4} \mathrm{~F}_{3 / 2}$ state depending on the excitation and emission wavelengths, allow emission from $\mathrm{Nd}^{3+}$ ions in the $\mathrm{LaF}_{3}$ nanocrystals to be identified and correlated with the structural properties. As the $\mathrm{Nd}^{3+}$ concentration is increased beyond $0.1 \mathrm{~mol} \%$, a stronger quenching of lifetime is observed for $\mathrm{Nd}^{3+}$ ions residing in $\mathrm{LaF}_{3}$ crystals than for those dispersed in the glass matrix. This strong concentration quenching is explained by the much higher concentration of $\mathrm{Nd}^{3+}$ ions in the crystalline phase with respect to that in the glass matrix.
\end{abstract}




\section{Introduction}

The growing field of photonics demands the design of new rare-earth (RE)-based optical materials for their use in optical telecommunications, solid-state lasers, threedimensional full-colour displays, solar cells, and other applications [1], [2], [3], [4] and [5]. Oxyfluoride glass-ceramics are promising RE-hosting candidates due to their good processing and optical properties [6]. They combine the good chemical and mechanical stability of oxide-glass matrices with the excellent optical properties of low-phononenergy fluoride nano-crystals.

Since 1993, when Wang and Ohwaki [7] obtained for the first time transparent oxyfluoride glass-ceramics containing $\mathrm{Pb}_{\mathrm{x}} \mathrm{Cd}_{1-\mathrm{x}} \mathrm{F}_{2}$ fluoride crystals doped with $\mathrm{Er}^{3+}$ and $\mathrm{Yb}^{3+}$ ions, the number of publications on transparent glass-ceramics has grown increasingly. Many compositions have been studied in recent years with the aim of obtaining different crystalline phases. Good review articles concerning oxyfluoride glass-ceramics have been published by A. de Pablos et al. [8] and Federov et al. [9].

A general glass system suitable for preparing glass-ceramics containing $\mathrm{LaF}_{3}$ nanocrystals by the melt-quenching method is $\mathrm{SiO}_{2}-\mathrm{Al}_{2} \mathrm{O}_{3}-\mathrm{Na}_{2} \mathrm{O}-\mathrm{LaF}_{3}$. The percentage of $\mathrm{SiO}_{2}$ generally varies between 40-65 mol\%, with other components in the following ranges: $\mathrm{Al}_{2} \mathrm{O}_{3}, 18-30 \mathrm{~mol} \% ; \mathrm{Na}_{2} \mathrm{O}, 10-20 \mathrm{~mol} \%$; and $\mathrm{LaF}_{3}$ 10-15 mo \%. A relevant parameter for assessing $\mathrm{LaF}_{3}$ crystallization ability is the ratio $\mathrm{Na}_{2} \mathrm{O} /\left(\mathrm{SiO}_{2}+\mathrm{Al}_{2} \mathrm{O}_{3}\right)$ since $\mathrm{La}$ tends to compensate the electrical charge of the $\left[\mathrm{AlO}_{4}\right]$ and $\left[\mathrm{SiO}_{4}\right]$ tetrahedra only in oxygen bonds which are not saturated by $\mathrm{Na}^{+}$ions [10].

Many $\mathrm{RE}$ ions have been used to dope glass-ceramics with $\mathrm{LaF}_{3}$ nano-crystals for different photonic applications. These include $\mathrm{Er}^{3+}$ for telecommunications at $1.55 \mu \mathrm{m}$ and for up-conversion (UC), $\mathrm{Pr}^{3+}$ for telecommunications at $1.3 \mu \mathrm{m}, \mathrm{Tm}^{3+}$ and $\mathrm{Tb}^{3+} / \mathrm{Yb}^{3+}$ for blue and green $\mathrm{UC}, \mathrm{Tm}^{3+} / \mathrm{Yb}^{3+}$ for down-conversion (DC), and $\mathrm{Nd}^{3+}$ and $\mathrm{Ho}^{3+} / \mathrm{Tm}^{3+}$ for infrared (IR) laser emission at 1.06 and $2 \mu \mathrm{m}$, respectively [11], [12], [13], [14], [15], [16], [17], [18], [19] and [20].

In this paper, an oxyfluoride glass with composition in mol $\% 55 \mathrm{SiO}_{2}-20 \mathrm{Al}_{2} \mathrm{O}_{3}$ $154 \mathrm{Na}_{2} \mathrm{O}-10 \mathrm{LaF}_{3}(55 \mathrm{Si}-10 \mathrm{La})$ doped with several $\mathrm{Nd}^{3+}$ concentrations $(0.1-2 \mathrm{~mol} \%)$ is investigated. The choice of this glass composition, previously developed in our research group [17], [21] and [22], relies on the fact that very small $\mathrm{LaF}_{3}$ crystals $(\sim 10 \mathrm{~nm})$, which is one of the best fluoride hosts for RE ions, can precipitate in the glass matrix. As a consequence, very good transparency is still obtained upon the conversion of the glass into a glass-ceramic. Moreover, this glass system has a peculiar feature: phase separation acts as a precursor to crystallization, with several $\mathrm{LaF}_{3}$ crystals tending to grow inside phase-separation droplets uniformly distributed throughout the glass matrix, thus impeding formation of clusters. In a previous work, $\mathrm{Tm}^{3+}$-doped $55 \mathrm{Si}-10 \mathrm{La}$ glassceramics were studied by X-ray absorption near-edge structure XANES spectroscopy and extended X-ray absorption fine structure (EXAFS) spectroscopy with X-ray synchrotron radiation [23]. These techniques revealed that $\mathrm{Tm}^{3+}$ incorporates preferentially into the $\mathrm{LaF}_{3}$ nanocrystals by diffusion, the concentration of which increases with treatment time. For a thermal treatment of $10 \mathrm{~h}$ at $620{ }^{\circ} \mathrm{C}$, the incorporation of $\mathrm{Tm}^{3+}$ ions in the $\mathrm{LaF}_{3}$ nanocrystals was about $17 \%$, reaching $30 \%$ for $40 \mathrm{~h}$ of heat treatment.

Among the rare-earth ions, $\mathrm{Nd}^{3+}$ has been recognized as one of the most efficient for solid-state lasers in crystals and glasses due to its intense ${ }^{4} \mathrm{~F}_{3 / 2} \rightarrow{ }^{4} \mathrm{I}_{11 / 2}$ emission at around $1.06 \mu \mathrm{m}$ [24]. Besides the interest of the $\mathrm{Nd}^{3+}$ ion for infrared (IR) optical amplification, it can also be used as a probe for local ordering due to the close relation between its spectroscopic properties and the local structure and bonding at the ion site [24] and [25]. However, there are few works on the laser properties of $\mathrm{Nd}^{3+}$ in transparent oxyfluoride glass-ceramics [26], [27], [28], [29], [30], [31], [32], [33], [34], [35] and [36]. In some of these studies, the spectroscopic properties of $\mathrm{Nd}^{3+}$-containing glass-ceramics differ very 
little from those of the precursor glasses, suggesting a more difficult incorporation of $\mathrm{Nd}^{3+}$ ions into the crystalline phase compared to other RE ions. Pisarska et al. [28] and [29] did not find any difference in the fluorescence lifetime of the ${ }^{4} \mathrm{~F}_{3 / 2}$ state in a heattreated sample of an oxyfluoroborate glass, concluding that $\mathrm{Nd}^{3+}$ ions are not incorporated in the crystalline phase. Yu et al. [19] studied $\mathrm{Nd}^{3+}$-doped $(0.5-3 \mathrm{~mol} \%)$ glass-ceramics where $\mathrm{LaF}_{3}$ precipitates with a crystal size between 10 to $15 \mathrm{~nm}$. It was found that the most promising composition was that containing $0.5 \mathrm{~mol} \% \mathrm{Nd}^{3+}$, in which glass-ceramics are more efficient than glasses. However, no deeper study of photoluminescence was performed.

In this work, the crystallisation mechanism and the structural and optical properties of $\mathrm{Nd}^{3+}$-doped $\mathrm{LaF}_{3}$ glass-ceramics are reported for their possible use as laser materials. In particular, the effect of $\mathrm{Nd}^{3+}$ ions on the kinetics of crystallisation has been studied and the possibility to selectively separate the emission of $\mathrm{Nd}^{3+}$ ions in the glass matrix from those embedded in $\mathrm{LaF}_{3}$ nanocrystals is presented. Site-selective emission and excitation spectra together with the different lifetime values of the ${ }^{4} \mathrm{~F}_{3 / 2}$ state depending on the excitation and emission wavelengths allows the emission of $\mathrm{Nd}^{3+}$ ions in $\mathrm{LaF}_{3}$ nanocrystals to be unambiguously identified which shows extremely well defined spectra similar to those obtained for pure $\mathrm{LaF}_{3}$ crystals [37], [38] and [39].

\section{Experimental}

\subsection{Materials and methods}

Glasses of composition $55 \mathrm{SiO}_{2}-20 \mathrm{Al}_{2} \mathrm{O}_{3}-15 \mathrm{Na}_{2} \mathrm{O}-10 \mathrm{LaF}_{3}$ (55Si-10La) doped with 0.1 , $0.2,0.5,1$ and $2 \mathrm{Nd}^{3+}$ (in mol\%) have been prepared by melting-quenching using as raw materials: $\mathrm{SiO}_{2}$ sand (Saint-Gobain, 99.6\%), $\mathrm{Al}_{2} \mathrm{O}_{3}$ (Panreac), $\mathrm{Na}_{2} \mathrm{CO}_{3}$ (Sigma Aldrich, $>99.5 \%$ ), $\mathrm{LaF}_{3}$ (Alfa Aesar, 99.9\%) and $\mathrm{NdF}_{3}$ (Alfa Aesar, 99.99\%). The batches were calcined at $1200{ }^{\circ} \mathrm{C}$ for $2 \mathrm{~h}$, melted at $1650{ }^{\circ} \mathrm{C}$ for $1.5 \mathrm{~h}$ and then quenched onto a brass mould. Glasses were melted again for $30 \mathrm{~min}$ and quenched onto a cold $\left(-10^{\circ} \mathrm{C}\right)$ brass mould. All the glasses were annealed at $600^{\circ} \mathrm{C}$ for $30 \mathrm{~min}$ to eliminate residual stresses. From now on, glass samples will be labelled as G0.1, G0.2, G0.5, G1 and G2, for $\mathrm{Nd}^{3+}$ concentrations of $0.1,0.2,0.5,1$, and 2 mol.\% respectively; corresponding glassceramics will be denoted with GCx.

Glass-ceramics samples were obtained by heat treatments of glass pieces at $620{ }^{\circ} \mathrm{C}$ for 1 , $3,5,20,40,80 \mathrm{~h}$ and at $660{ }^{\circ} \mathrm{C}-20 \mathrm{~h}$, using a heating rate of $10^{\circ} \mathrm{C} / \mathrm{min}$. Glass sheets $(1 \mathrm{~cm} \times 1 \mathrm{~cm} \times 2 \mathrm{~mm})$ were treated and then polished for optical characterization. One glass slab for each composition was not treated and used as reference glass to compare with the corresponding glass-ceramics.

\subsection{Structural characterisation}

Non-isothermal crystallisation kinetics were studied by DTA/TG (SDT Q600 - TA Instruments) using $20-30 \mathrm{mg}$ of glass with particle size in the range $1-1.25 \mathrm{~mm}$. DTA curves were obtained with heating rates in the range $10-60{ }^{\circ} \mathrm{C} / \mathrm{min}$. From these DTA data, the glass transition temperature $\mathrm{T}_{\mathrm{g}}$, Avrami $n$ parameter and crystal-growth dimensionality $m$ parameter were calculated from the Ozawa equation [40] and the Matusita equation [41] given by equations (1) and (2) respectively:

$$
\begin{gathered}
\left(\frac{d[\ln [-\ln (1-x)]]}{d(\ln q)}\right)_{T}=-n \\
\ln \left(\frac{q^{n}}{T_{p}^{2}}\right)=-\frac{m E_{a}}{R T_{p}}+\text { Cost }
\end{gathered}
$$


In these relations, $x$ is the partial area of the crystallisation peak calculated for a fixed temperature $T$ and $q$ is the heating rate; $T_{p}$ and $R$ are the crystallisation peak temperature and the gas constant, respectively. The activation energy for crystallisation $E_{a}$ was calculated using the Kissinger equation [42]:

$$
\ln \left(\frac{q}{T_{p}^{2}}\right)=-\frac{E_{a}}{R T_{p}}+\operatorname{Cost}
$$

The heat-treated specimens were milled, sieved $(<63 \mu \mathrm{m})$ and characterised by XRD (Bruker D8 Advance diffractometer). XRD diffractograms were acquired in the range $2 \theta$ 10-70, with a step-size of $0.02^{\circ}$ and $1 \mathrm{~s}$ acquisition time for each step. The crystal size was calculated using the Scherrer equation [43]:

$$
D=\frac{0.94 \lambda}{\cos \theta \sqrt{B_{m}^{2}-B_{i}^{2}}}
$$

where $\lambda$ is the wavelength $\left(1.54056 \AA-\mathrm{CuK} \alpha_{1}\right), \mathrm{B}_{\mathrm{m}}$ the full width half maximum of the $\mathrm{LaF}_{3}$ peak (111) and $\theta$ its diffraction angle. The factor 0.94 corresponds to spherical crystals. The pseudo-Voigt function was used to fit diffraction-peak parameters. The instrumental broadening $B_{i}$ has also been taken into account using $\mathrm{NaF}$ powder properly milled and sieved $(<63 \mu \mathrm{m})$.

The crystallised fraction of $\mathrm{LaF}_{3}$ in the glass-ceramics obtained on a heat treatment at $620^{\circ} \mathrm{C}$ for 40 hours was estimated by quantitative Rietveld analysis employing a method that has been applied to similar compositions [17] and [22]. The glass was finely ground in an agate mortar, sieved through a $60 \mu \mathrm{m}$ mesh then milled again with $\mathrm{NaF}$ (99.9\%), which was used as internal standard in an appropriate quantity $(5-6 \mathrm{wt} \%)$ to approximate the peak intensity of the nanocrystalline $\mathrm{LaF}_{3}$. XRD powder data for Rietveld analysis were collected over the range $10^{\circ} \leq 2 \theta \leq 90^{\circ}$ in a stepwidth of $0.0289^{\circ}$ and a counting time of 4s per step employing a Bruker D8 high-resolution diffractometer equipped with a solid-state rapid LynxEye detector, and monochtomatic $\mathrm{Cu} \mathrm{K} \alpha_{1}$ radiation. Rietveld refinement was performed with the Fullprof program using interpolation of background points to model the amorphous contribution to the pattern.

TEM samples of glasses and glass-ceramics were prepared using sieved powders of size $<63 \mu \mathrm{m}$. High resolution electron microscopy (HR-TEM), including Scanning Transmission Electron Microscopy-High Angle Annular Dark Field (STEM-HAADF) were recorded on a JEOL 2100 field-emission gun transmission electron microscope operating at $200 \mathrm{kV}$ with a point resolution of $0.19 \mathrm{~nm}$. The microscope is equipped with an energy dispersive X-ray spectrometer (EDXS) (INCA x-sight, Oxford Instruments), which was operated in STEM mode, with a probe size of $1 \mathrm{~nm}$.

Small-angle X-ray scattering (SAXS) measurements were performed using a commercial SAXS system (SAXSess, Anton Paar GmbH). The bulk samples were crushed into fine powders and then compressed into uniform thin pellets for the SAXS measurements. A $\mathrm{Cu} \mathrm{K \alpha}$ line beam of $10 \mathrm{~mm} \times 0.4 \mathrm{~mm}$ in size was incident on the samples, and the scattered X-rays were collected using an imaging plate in the q range of $0.01-0.1 \AA^{-1}$. The collected 2D patterns were converted into $1 \mathrm{D}$ patterns and treated using the linebeam profile. The 1D SAXS data were then analysed using the Irena software package ${ }^{44}$ to obtain the particle-size distribution.

\subsection{Optical characterisation}

UV-Vis absorption spectra of optical sheets were measured in the range 300-1000 nm using a Lamba 900-Perkin Elmer double-beam spectrophotometer. 
Site-selective, steady-state emission and excitation spectra were recorded by exciting the samples with a continuous wave (cw) Ti:sapphire ring laser $\left(0.4 \mathrm{~cm}^{-1}\right.$ linewidth) in the $770-920 \mathrm{~nm}$ spectral range. The fluorescence was analysed with a $0.25 \mathrm{~m}$ monochromator; the signal was detected by an extended IR Hamamatsu H10330A-75 photomultiplier and amplified by a standard lock-in technique. The sample temperature was varied between 10 and $300 \mathrm{~K}$ in a continuous-flow cryostat.

Lifetime measurements were obtained by exciting the samples with a Ti:sapphire laser pumped by a pulsed frequency-doubled Nd:YAG laser ( 9 ns pulse width), and detecting the emission with a Hamamatsu H10330A-75 photomultiplier. Data were processed by a Tektronix oscilloscope.

\section{Results and discussion}

\subsection{Structural properties}

Fig. 1a shows DTA curves for G0.1 for the heating rates $10-60{ }^{\circ} \mathrm{C} / \mathrm{min}$. The exothermic peak, $\mathrm{T}_{\mathrm{p}}$, at around $670{ }^{\circ} \mathrm{C}$ corresponds to the crystallisation of $\mathrm{LaF}_{3}$ phase. Similar results were obtained for the undoped glass [22]. Fig. $1 \mathrm{~b}$ shows the variation of $\mathrm{T}_{\mathrm{g}}$ and $\mathrm{T}_{\mathrm{p}}$ with $\mathrm{Nd}^{3+}$ concentration for a heating rate of $10{ }^{\circ} \mathrm{C} / \mathrm{min}$, the same rate as used in all heat treatments. On increasing the $\mathrm{Nd}^{3+}$ concentration, $\mathrm{T}_{\mathrm{g}}$ changes almost linearly from a value of $573{ }^{\circ} \mathrm{C}$ for the G0.1 sample to $593{ }^{\circ} \mathrm{C}$ for $\mathrm{G} 2$, while $\mathrm{T}_{\mathrm{p}}$ changes only a few degrees for increasing $\mathrm{Nd}^{3+}$ contents. The crystallisation stability parameter, $\Delta \mathrm{T}=\mathrm{T}_{\mathrm{p}}-\mathrm{T}_{\mathrm{g}}$, diminishes notably with higher $\mathrm{Nd}^{3+}$ concentration, with G2 glasses showing a higher tendency to crystallise compared to the G0.1 glass. It appears, therefore, that $\mathrm{Nd}^{3+}$ ions are acting as nucleating agent, and concomitantly increase the glass-matrix rigidity. This may be explained on considering that incorporation of $\mathrm{RE}$ ions usually increases glass viscosity in the high-viscosity regime, i.e for $\mathrm{T}<\mathrm{T}_{\mathrm{g}}$ [17] and [45]. Additionally, RE incorporation could favour phase separation, which also leads to an increase in viscosity.

Fig. 1 (c) shows the Ozawa plots of G0.1 for six different temperatures. For each plot, an $n$ value was obtained, and then a mean $n$ value was calculated and included in the figure together with the $m$ parameter. Similar $n$ and $m$ values, approximate to 1 , were obtained for all compositions. These values correspond to a crystallisation process which starts from a constant number of nuclei and for which crystal growth is diffusion controlled [46]. The same behaviour was also observed for other oxyfluoride GCs [47], [48] and [49]. The addition of $\mathrm{Nd}^{3+}$, even in quite varied concentrations, does not influence the crystallisation mechanism but affects the crystallisation kinetics. Moreover, the crystallisation activation energy, $E_{\mathrm{a}}$, around $350 \mathrm{~kJ} / \mathrm{mol}$, is the same for all compositions and similar to that of the undoped glass [22].
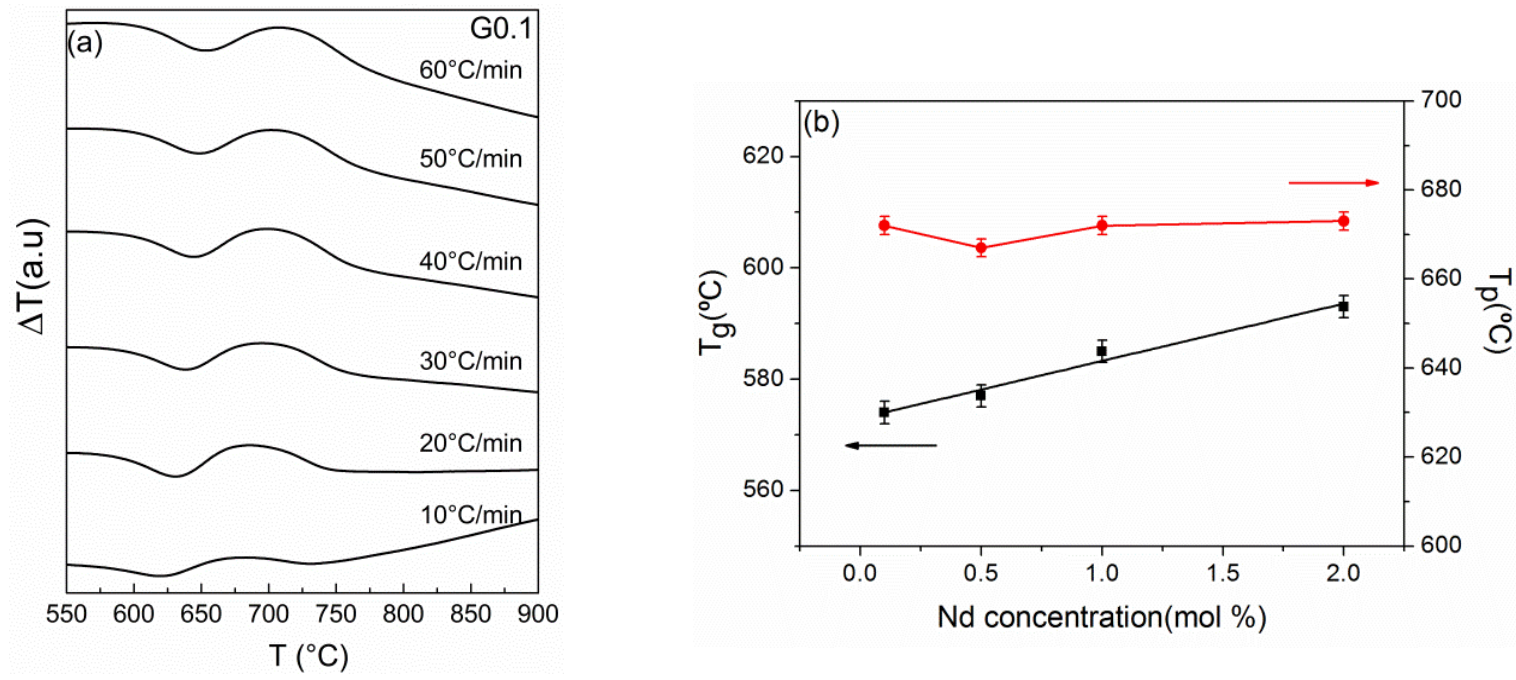


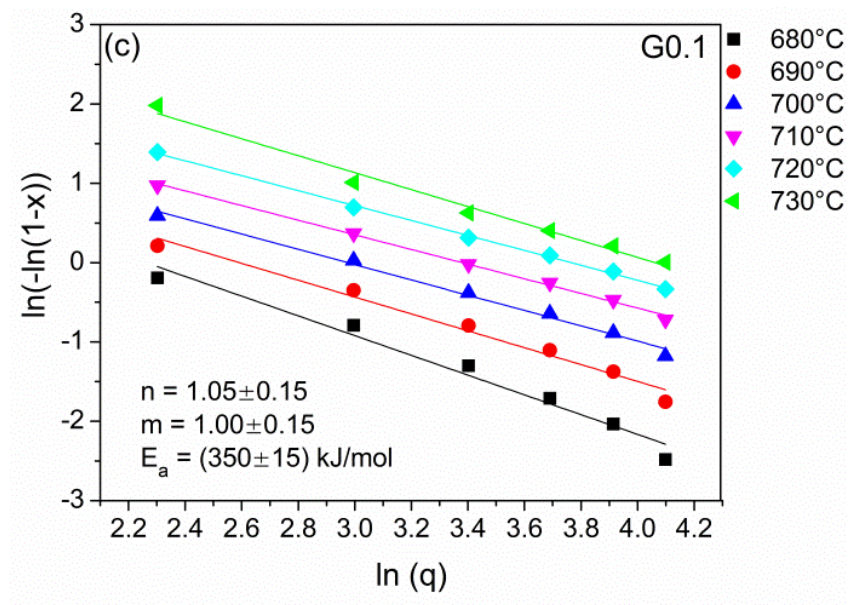

Fig. 1. (a) DTA curves at different heating rates of the G0.1 glass and (b) $\mathrm{Tg}$ variation with $\mathrm{Nd}$ concentration; (c) Ozawa plots.

Fig. 2(a) shows the XRD diffractograms of GC0.1 samples heat treated at $620{ }^{\circ} \mathrm{C}$ for $1,3,5,20$, 40 and $80 \mathrm{~h}$ and at $660{ }^{\circ} \mathrm{C}$ for $20 \mathrm{~h}$. $\mathrm{LaF}_{3}$ peaks (JCPDS 00-032-0483) are shown at the foot of the figure for reference. For all compositions, only $\mathrm{LaF}_{3}$ crystals precipitate in the glass matrix; however, the crystal-growth kinetics slows down as $\mathrm{Nd}^{3+}$ content increases. Fig. $2 \mathrm{~b}$ shows the crystal size of GCs at $620^{\circ} \mathrm{C}$ for all the $\mathrm{Nd}^{3+}$ concentrations; the crystal size for GCs at $660{ }^{\circ} \mathrm{C}$ is shown in the inset. On gradually increasing the $\mathrm{Nd}^{3+}$ concentration, the crystal size decreases for treatments at 620 and $660{ }^{\circ} \mathrm{C}$. On treatment at $620{ }^{\circ} \mathrm{C}, \mathrm{LaF}_{3}$ crystals grow from $10 \mathrm{~nm}$ to $12.5 \mathrm{~nm}$ during the first $5 \mathrm{~h}$ for the G0.1 glass, but grow less than $1 \mathrm{~nm}$ for G2. This may be explained on consideration of the higher $\mathrm{T}_{\mathrm{g}}$ of the $\mathrm{G} 2$ glass.

For heat treatment at $660{ }^{\circ} \mathrm{C}-20 \mathrm{~h}$ larger crystals are formed but a similar trend as observed for $620{ }^{\circ} \mathrm{C}$ is maintained. The inset of Fig. 2(b) shows the crystal growth rate for treatment at 620 ${ }^{\circ} \mathrm{C}$ in the range $1-5 \mathrm{~h}$, since for times longer than $20 \mathrm{~h}$ the crystal size does not change with time. Crystal-growth rate decreases from GC0.1 to GC1, maintaining practically the same value for GC2.

Quantitative Rietveld refinements of the $\mathrm{LaF}_{3}$ crystalline phase with $\mathrm{NaF}$ as internal standard were carried out for GCs obtained at the same thermal treatment of $620^{\circ} \mathrm{C}$ during $40 \mathrm{~h}$. The observed diffraction pattern and the difference between observed and calculated diffraction patterns for 0.1GC are shown in Fig. 2(c).
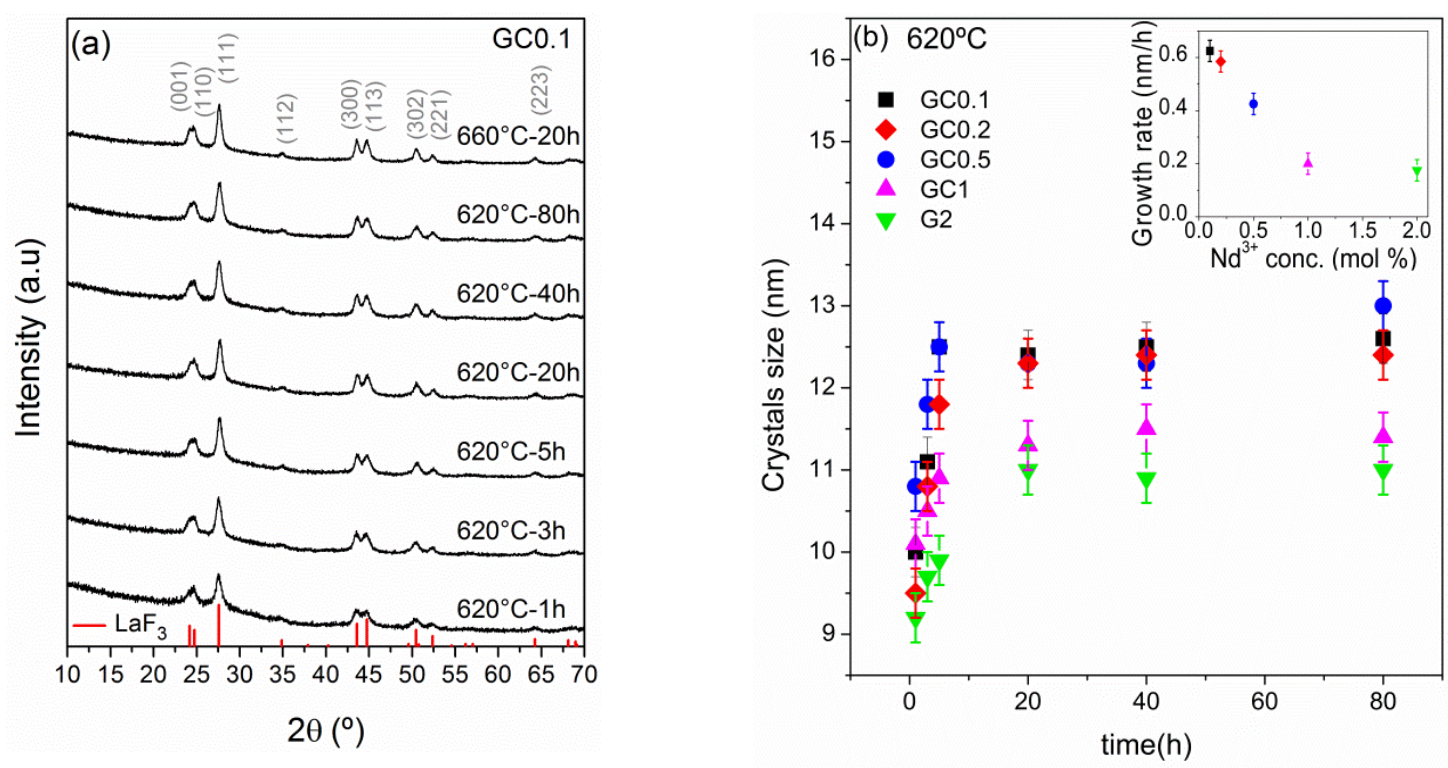


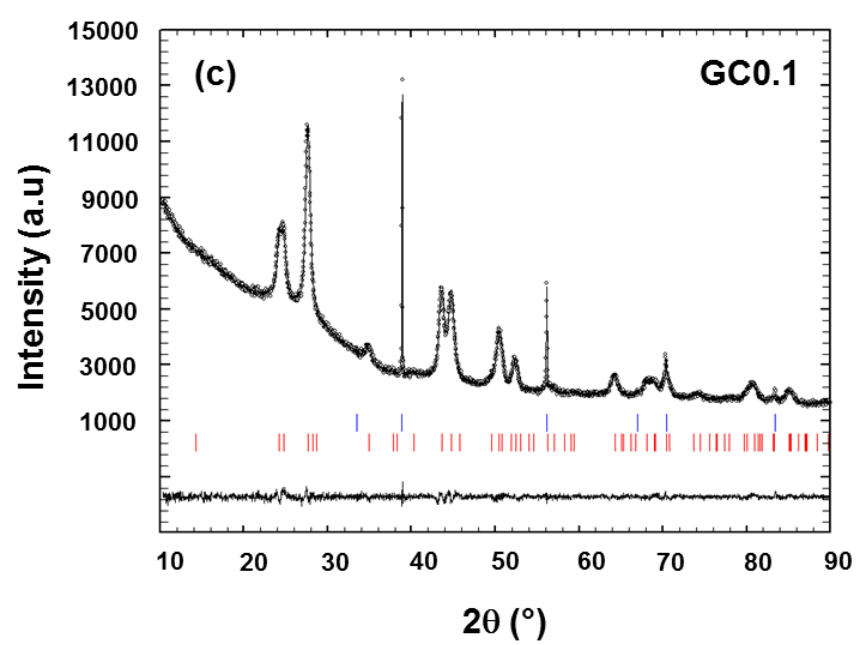

Fig. 2. (a) XRD diffractograms for $\mathrm{G} 0.1$ treated at $620^{\circ} \mathrm{C}$ for periods in the range $1-80 \mathrm{~h}$ and $\mathrm{G} 1660^{\circ} \mathrm{C}$ 20h G2; (b) Crystals size for GC samples G0.1, G0.2, G0.5, G1 and G2 treated at $620^{\circ} \mathrm{C}$ and (inset) crystals growth rate in the range 1-5 h; (c) Observed and difference X-ray powder diffraction profiles of GC0.1 obtained at $620{ }^{\circ} \mathrm{C}$ during $40 \mathrm{~h}$ with $5 \mathrm{~mol} \% \mathrm{NaF}$ internal weight standard. The Bragg peaks of $\mathrm{NaF}$ and $\mathrm{LaF}_{3}$ are indicated by top and bottom vertical bars, respectively. Refinement parameters $\mathrm{R}_{\mathrm{p}}=$ $1.53 ; \mathrm{R}_{\mathrm{wp}}=2.0 ; \chi^{2}=1.44$ were obtained.

The following crystalline fractions (wt \%) were determined with varying Nd content: 0.1GC (6.4), 0.5GC (9.9), 1GC (8.8), and 2GC (8.2). Although it is difficult to establish a clear tendency, it is apparent that an increase of the crystalline fraction takes place for $\mathrm{Nd}$ contents above $0.5 \mathrm{~mol} \%$, after which, the crystalline fraction tends to stabilise, or even slightly decrease, which is in good agreement with the smaller nanocrystals obtained with 1 and 2 mol \% of Nd (Fig. 2(b)).

Fig. 3a and 3b show HR-TEM images of G2 glass at different magnifications. The inset of Fig. 3a indicates the size of the initial phase-separated droplets present in the glass; their mean size is $34.8 \pm 0.4 \mathrm{~nm}$, the FWHM is $18 \pm 2 \mathrm{~nm}$. No crystalline structure was observed. Figs. $3 \mathrm{c}$ and $3 \mathrm{~d}$ show images of GC2 treated at $620{ }^{\circ} \mathrm{C}$ for $40 \mathrm{~h}$. The amorphous phase-separated droplets in the glass samples formed several crystals inside. The droplet and crystal size distribution are given in the insets of Figs. 3c and 3d, respectively. The mean value of the droplets in the GC sample is $34.0 \pm 0.4 \mathrm{~nm}$, similar to that obtained for the glass, but the FWHM gets sharper giving a value of $10 \pm 1 \mathrm{~nm}$; the mean crystal size is centred at $10 \mathrm{~nm}$, in agreement with the value obtained by XRD measurements for the $\mathrm{GC} 2620^{\circ} \mathrm{C}-40 \mathrm{~h}$ sample.

Figs. 3e and $3 \mathrm{f}$ present crystal planes along the [100] and [113] directions calculated by FFT of some crystals shown in Fig. $3 \mathrm{~d}$, confirming the precipitation of $\mathrm{LaF}_{3}$ crystals. The plane distances $\mathrm{d}_{111}$ and $\mathrm{d}_{113}$, which give the most intense peaks in the XRD diffractogram at $27.5^{\circ}$ and $44.7^{\circ} 2 \theta$, are $0.33 \mathrm{~nm}$ and $0.20 \mathrm{~nm}$, in good agreement with the values of $0.323 \mathrm{~nm}$ and $0.202 \mathrm{~nm}$ reported for $\mathrm{LaF}_{3}$ in the JCPDS (00-032-0483) and the literature [50], [51] and [52]. Fig. $3 \mathrm{~g}$ presents the EDX curves across two adjacent droplets circled in red in Fig. 3h; the points 1-2 and 3-4 delimit the first and second droplet, respectively. The yellow line is the scanning line, also represented in Fig. $3 \mathrm{~g}$ with the droplet size marked by vertical dashed grey lines. EDX analysis of Fig. $3 \mathrm{~g}$ shows Si enrichment surrounding the phase-separated droplets, which leads to the formation of a barrier of higher viscosity around them.

The barrier formation appears to occur during the first $20 \mathrm{~h}$ of heat treatment since $\mathrm{LaF}_{3}$ crystals grow during this time, and thereafter maintain their size. The incorporation of $\mathrm{Nd}^{3+}$ inside the $\mathrm{LaF}_{3}$ crystals is clearly visible from the EDX curves. 

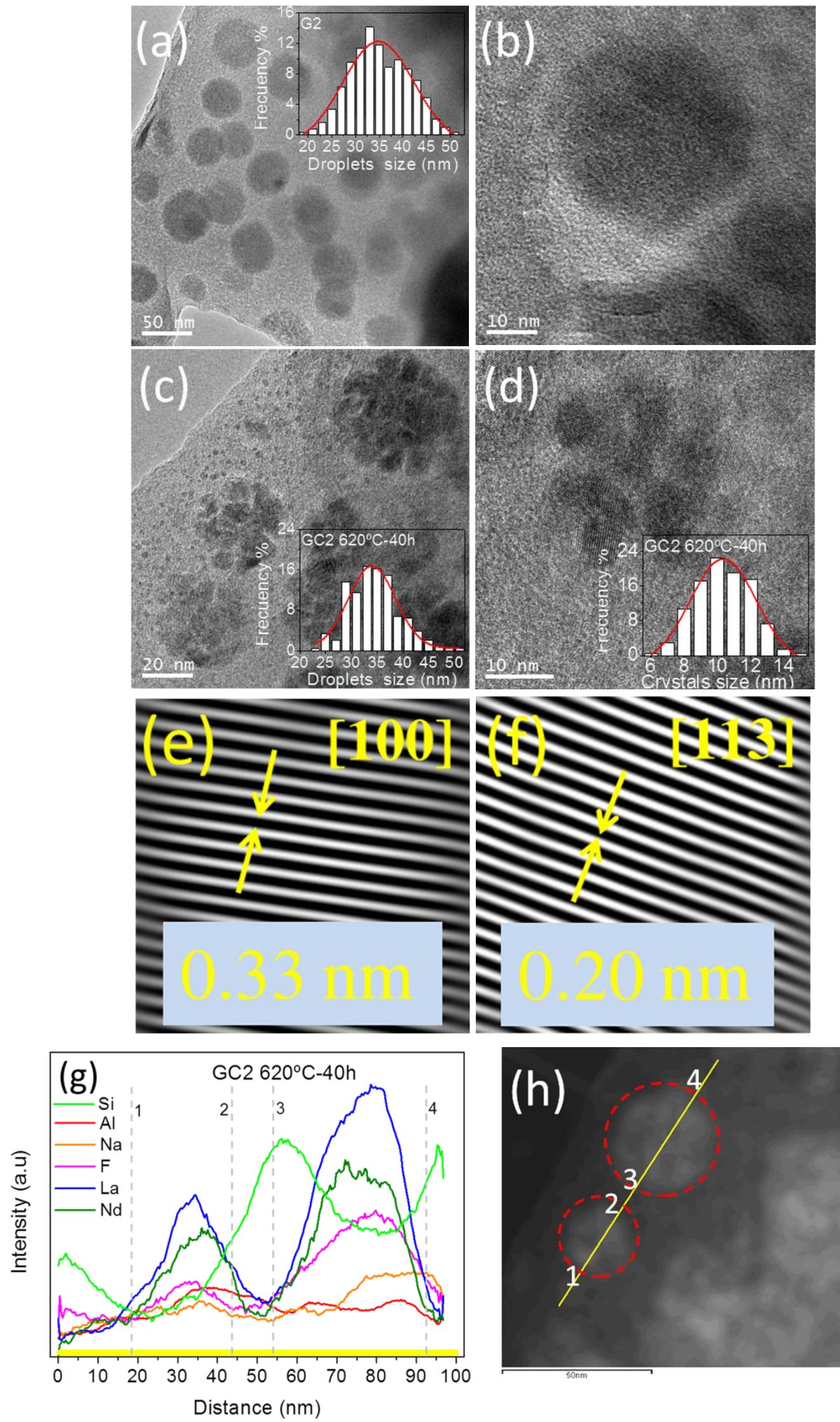
Fig. 3. (a) and (b) HR-TEM of G2 glass; (c) and (d) GC2 heat treated at $620{ }^{\circ} \mathrm{C}-40 \mathrm{~h}$; (e) and (f) lattice planes of some crystals shown in (d); (g) EDX of the GC2 $620{ }^{\circ} \mathrm{C}-40 \mathrm{~h}$ sample along 2 droplets containing several crystals (the yellow and light grey lines indicate the scanning line and droplet size, respectively); (h) STEM image of the droplets used for the EDX measurement where the yellow line is the same as that represented in $(\mathrm{g})$.

Fig. $4 \mathrm{a}$ and $4 \mathrm{~b}$ show the particle volume distribution of G2 and GC2 samples (annealed at $620^{\circ} \mathrm{C}$ for $40 \mathrm{hrs}$ ) as a function of particle diameter. The insets display the raw SAXS data and theoretical fit using the Irena program, from which the particle volume distribution was obtained. The particles can be classified in two distinctive size groups, group 1 below $10 \mathrm{~nm}$ and group 2 between 15 and $60 \mathrm{~nm}$. The group 1 particles seen in both samples may be associated with very small initial phase-separated droplets which could not grow sufficiently to produce crystals. The group 2 particle size is, however, in very good agreement with the results obtained by TEM and is related with the scattering of phase-separated droplets. The calculated average diameters for these two groups of particles were $6 \mathrm{~nm}$ and $38 \mathrm{~nm}$ for the G2 sample, and $7 \mathrm{~nm}$ and $36 \mathrm{~nm}$ for the GC2 sample.

The SAXS results were roughly consistent with the TEM results reported in Fig. 3. The slightly larger average size (by about $2 \mathrm{~nm}$ ) derived from the SAXS analysis compared to the TEM results could be due to the difference between particle-volume distribution (SAXS) and particlenumber distribution (TEM), with the former having more weighting on the larger particles. One interesting feature is that the two groups of particles showed opposite growth behaviour upon thermal annealing: the group 1 particle-size distribution became broader while that of the group 2 particles became narrower after $40 \mathrm{hrs}$ of annealing at $620^{\circ} \mathrm{C}$, which was consistent with the TEM observation. The thermal annealing also significantly enhanced the relative volume fraction of group 1 particles. New particles between 10 and $15 \mathrm{~nm}$ in diameter appeared in the GC2 sample after thermal annealing, which were probably related to the crystals as seen from the TEM and XRD results.
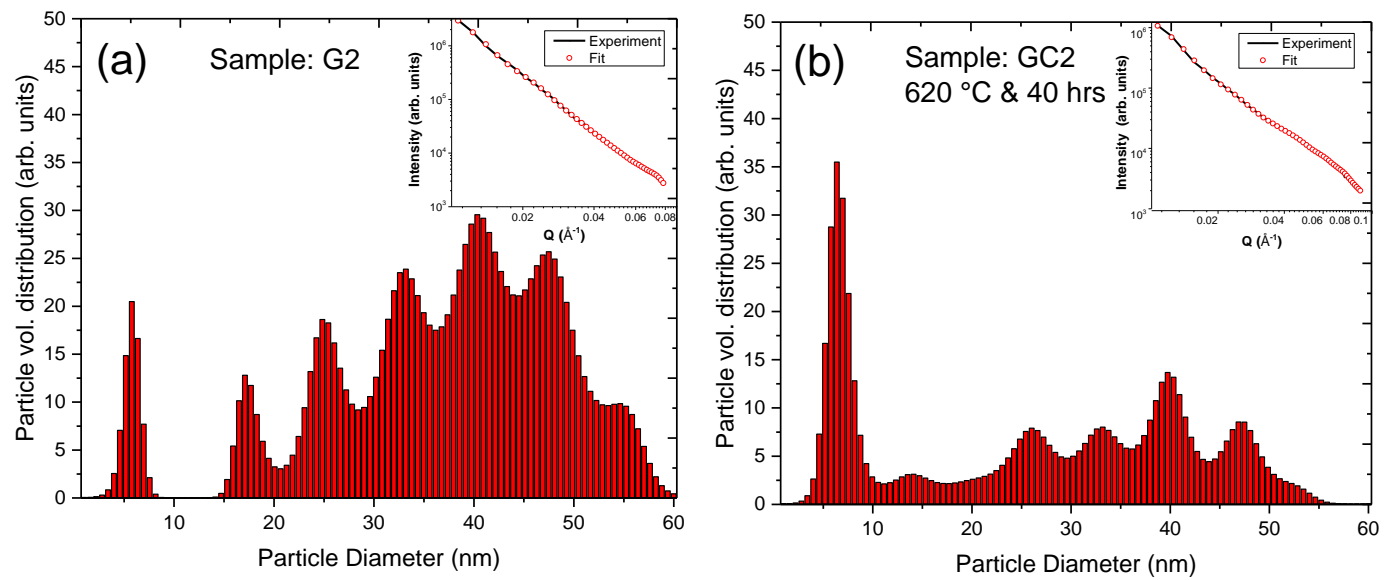

Fig. 4. SAXS data (insets) and derived particle-volume distribution of G2 (a) and GC2-620 ${ }^{\circ} \mathrm{C}$ treated for 40 hrs (b).

\subsection{Absorption and emission properties}

A further proof of $\mathrm{Nd}^{3+}$ incorporation in the $\mathrm{LaF}_{3}$ crystals comes from UV-Vis absorption spectra in Fig. 5, in which GCs samples are compared with glasses. Figs 5a 
and $5 \mathrm{~b}$ show the absorption coefficient for the G0.1, G0.2, G0.5, G1 and G2 glasses and for the corresponding GC samples treated at $620^{\circ} \mathrm{C}$ for $40 \mathrm{~h}$. The bands observed in the spectra correspond to transitions from the fundamental level $\left({ }^{4} \mathrm{I}_{9 / 2}\right)$ to each of the excited levels of $\mathrm{Nd}^{3+}$ ions. The glass samples present characteristic inhomogeneouslybroadened absorption bands. However, in the case of the GC samples, the absorption bands are resolved better, indicating the incorporation of $\mathrm{Nd}^{3+}$ ions in the $\mathrm{LaF}_{3}$ nanocrystals precipitated during the heat treatments.

Fig. 5c presents the ${ }^{4} \mathrm{I}_{9 / 2} \rightarrow{ }^{4} \mathrm{G}_{5 / 2},{ }^{2} \mathrm{G}_{7 / 2}$ absorption bands of G0.1 and G2 glasses, along with GC0.1 and GC2 glass-ceramics treated at $620{ }^{\circ} \mathrm{C}$ for $40 \mathrm{~h}$, in greater detail. The absorption bands ${ }^{4} \mathrm{I}_{9 / 2} \rightarrow{ }^{4} \mathrm{~F}_{7 / 2},{ }^{4} \mathrm{~S}_{3 / 2}$ and ${ }^{4} \mathrm{I}_{9 / 2} \rightarrow{ }^{4} \mathrm{~F}_{5 / 2},{ }^{2} \mathrm{H}_{9 / 2}$ in the GC samples are shown in the inset. Similar behaviour is also appreciable in the GC samples treated at $620{ }^{\circ} \mathrm{C}$ and $660{ }^{\circ} \mathrm{C}$ for $20 \mathrm{~h}$. The ${ }^{4} \mathrm{I}_{9 / 2} \rightarrow{ }^{4} \mathrm{G}_{5 / 2}$ transition is well known to be a hypersensitive transition, exhibiting an electric quadrupole character which is strongly dependent on the ligand field. A clear change in the absorption band allows the Stark components in the GCs to be better resolved. The sharpening of the band in comparison to the initial glass indicates the presence of $\mathrm{Nd}^{3+}$ ions inside the $\mathrm{LaF}_{3}$ crystals. This is most clearly visible in the G0.1 sample, whereas on increasing the $\mathrm{Nd}^{3+}$ content, the difference between glass and GCs is less apparent.
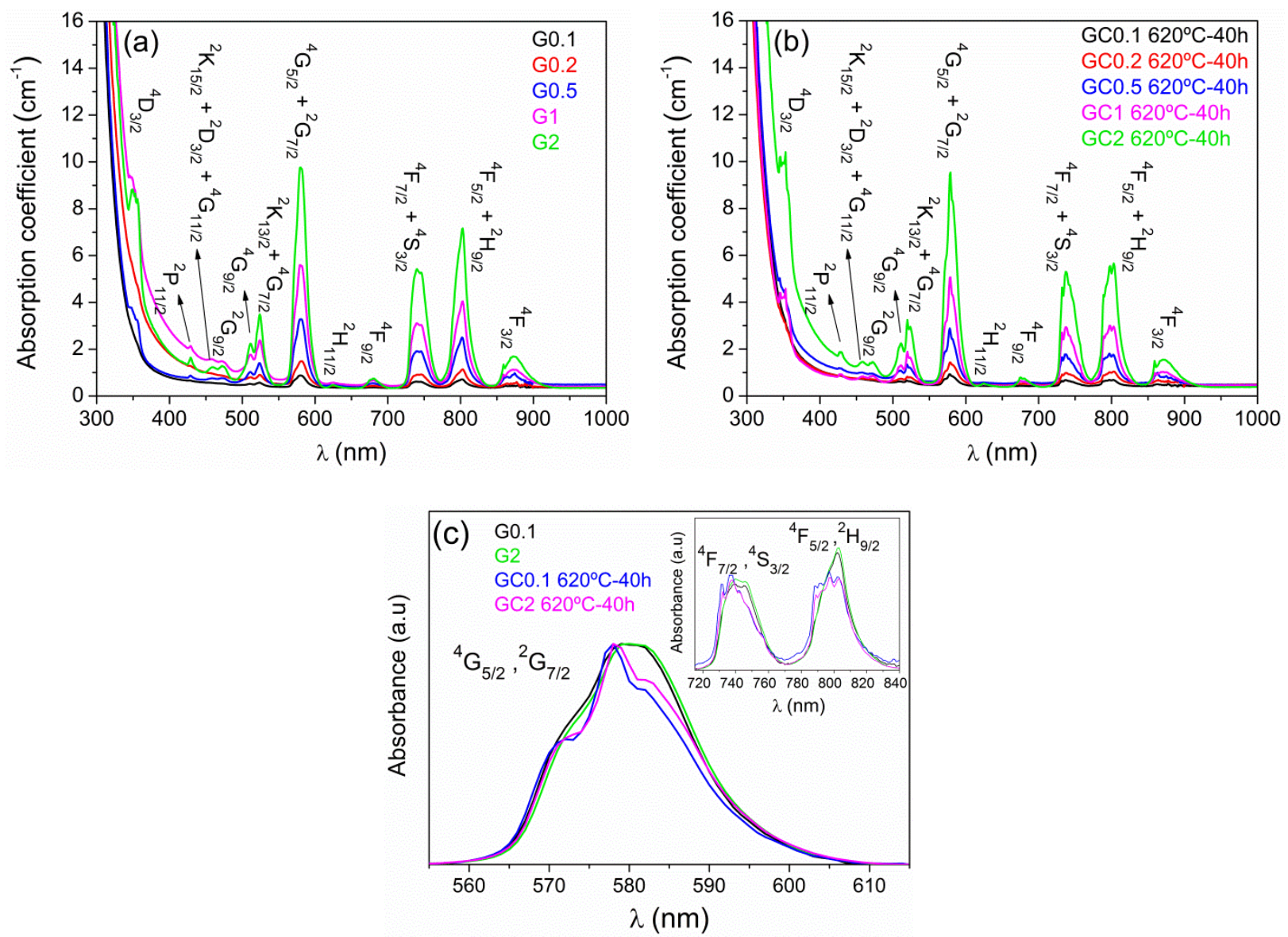

Fig. 5. (a) Absorption spectra of glasses G0.1, G0.5, G1, G2 and (b) GCs treated at $620{ }^{\circ} \mathrm{C}-40 \mathrm{~h}$; (c) comparison of absorption transitions ${ }^{4} \mathrm{I}_{9 / 2} \rightarrow{ }^{4} \mathrm{G}_{5 / 2},{ }^{2} \mathrm{G}_{7 / 2}$ and (inset) ${ }^{4} \mathrm{I}_{9 / 2}$ $\rightarrow{ }^{4} \mathrm{~F}_{7 / 2},{ }^{4} \mathrm{~S}_{3 / 2}$ and ${ }^{4} \mathrm{I}_{9 / 2} \rightarrow{ }^{4} \mathrm{~F}_{5 / 2},{ }^{2} \mathrm{H}_{9 / 2}$ in G0.1, G2, GC0.1 $620{ }^{\circ} \mathrm{C}-40 \mathrm{~h}$ and GC2 $620{ }^{\circ} \mathrm{C}-$ $40 \mathrm{~h}$. 
The absorption bands of the glass and GC samples doped with $2 \mathrm{~mol} \% \mathrm{Nd}^{3+}$, together with the values of the refractive index and $\mathrm{Nd}^{3+}$ concentration, have been used to determine the Judd-Ofelt parameters [53] and [54]. Using this theory, the calculated oscillator strengths can be expressed as a function of the reduced-matrix elements $\left|U^{\prime}\right|$ which are almost independent of the ion environment. To estimate the $\mathrm{J}-\mathrm{O}$ parameters (Table 1), the values reported by Carnall et al. for $\mathrm{Nd}^{3+}$ in $\mathrm{LaF}_{3}$ [55] were employed. As is well known, the spectroscopic parameter $\Omega_{2}$ is proportional to the covalent nature of the chemical bonding between rare-earth ions and ligand ions [56]. As observed in Table $1, \Omega_{2}$ decreases from $3.23 \times 10^{-20}$ in the glass sample to $2.82-2.89 \times 10^{-20}$ in the GC materials. That is, the heat treatment induces a reduction in the degree of covalence between $\mathrm{Nd}^{3+}$ and its nearest neighbours. The decrease of $\Omega_{2}$ further confirms the incorporation of $\mathrm{Nd}^{3+}$ ions into the precipitated nanocrystals. Moreover, the sum of the $\mathrm{J}$ $\mathrm{O}$ parameters decreases for the GC samples due to the decreasing covalency of the bond between the $\mathrm{Nd}^{3+}$ ion and surrounding anions in accordance with reported results [57].

The strength of the hypersensitive ${ }^{4} \mathrm{I}_{9 / 2} \rightarrow{ }^{4} \mathrm{G}_{5 / 2}$ transition, which is greatly affected by the environment of $\mathrm{Nd}^{3+}$ ions, is dominated by the $\Omega_{2}$ parameter contribution, increasing with both the ligand polarisability and asymmetry of the surrounding environment [53] and [54]. The oscillator strength of this transition is reduced from $1796 \times 10^{-8}$ in the glass to $1609 \times 10^{-8}, 1581 \times 10^{-8}$, and $1591 \times 10^{-8}$ in the GC $620^{\circ} \mathrm{C} \mathrm{C}-20 \mathrm{~h}, \mathrm{GC} 620{ }^{\circ} \mathrm{C}-40 \mathrm{~h}$, and GC $660{ }^{\circ} \mathrm{C}-20 \mathrm{~h}$ samples, respectively. This tendency confirms that the ligand field around the $\mathrm{Nd}^{3+}$ ions changes as a consequence of the heat treatment and crystallisation process.

Table 1. Judd-Ofelt parameters and r.m.s. deviation for precursor glass and GC samples doped with $2 \mathrm{~mol} \% \mathrm{Nd}$

\begin{tabular}{|c|c|c|c|c|}
\hline Sample & $\Omega_{2}\left(\times 10^{-20}\right)$ & $\Omega_{4}\left(\times 10^{-20}\right)$ & $\Omega_{6}\left(\times 10^{-20}\right)$ & r.m.s. \\
\hline Glass & 3.23 & 6.23 & 5.03 & $5.35 \cdot 10^{-7}$ \\
\hline $\mathrm{GC} 2-620^{\circ} \mathrm{C}-20 \mathrm{~h}$ & 2.85 & 5.57 & 4.37 & $5.25 \cdot 10^{-7}$ \\
\hline $\mathrm{GC} 2-620^{\circ} \mathrm{C}-40 \mathrm{~h}$ & 2.82 & 5.48 & 4.31 & $5.16 \cdot 10^{-7}$ \\
\hline $\mathrm{GC} 2-660^{\circ} \mathrm{C}-20 \mathrm{~h}$ & 2.89 & 5.45 & 4.17 & $5.35 \cdot 10^{-7}$ \\
\hline
\end{tabular}

The spontaneous emission probabilities from the ${ }^{4} \mathrm{~F}_{3 / 2}$ to ${ }^{4} \mathrm{I}_{\mathrm{J}}$ states were calculated from the $\mathrm{J}-\mathrm{O}$ parameter and used to obtain the radiative lifetimes.

The ${ }^{4} \mathrm{~F}_{3 / 2} \rightarrow{ }^{4} \mathrm{I}_{11 / 2,13 / 2}$ steady-state fluorescence spectra were measured at room temperature for all samples by exciting with a Ti:sapphire laser at $802 \mathrm{~nm}$ in resonance with the ${ }^{4} \mathrm{I}_{9 / 2} \rightarrow{ }^{4} \mathrm{~F}_{5 / 2},{ }^{2} \mathrm{H}_{9 / 2}$ absorption band. Fig. 6 shows the emission for the samples doped with 2 mol\% Nd. It can be seen that the emission is inhomogeneously broadened due to site-tosite variations in the local ligand field. The fluorescence band for the ${ }^{4} \mathrm{~F}_{3 / 2} \rightarrow{ }^{4} \mathrm{I}_{11 / 2}$ emission was integrated and divided by the peak intensity to yield an effective linewidth [57]. From the measured effective linewidth and the spontaneous emission probability of the ${ }^{4} \mathrm{~F}_{3 / 2} \rightarrow{ }^{4} \mathrm{I}_{11 / 2}$ laser transition, calculated from the $\mathrm{J}-\mathrm{O}$ parameters, the stimulated emission cross-section of this transition may be evaluated as [58]:

$$
\sigma_{p}\left(\lambda_{p}\right)=\frac{\lambda_{p}^{4}}{8 \pi c n^{2} \Delta \lambda_{\text {eff }}} A\left[\left({ }^{4} F_{3 / 2}\right),\left({ }^{4} I_{11 / 2}\right)\right]
$$

where $\lambda_{p}$ is the peak fluorescence wavelength, $n$ is the refractive index, $\Delta \lambda_{\text {eff }}$ is the effective linewidth of the ${ }^{4} \mathrm{~F}_{3 / 2} \rightarrow{ }^{4} \mathrm{I}_{11 / 2}$ transition, and $A\left[\left({ }^{4} F_{3 / 2}\right) ;\left({ }^{4} I_{11 / 2}\right)\right]$ is the radiative transition probability for this transition.

The stimulated emission cross-section for the ${ }^{4} \mathrm{~F}_{3 / 2} \rightarrow{ }^{4} \mathrm{I}_{11 / 2}$ transition and other relevant parameters are presented in Table 2. The peak position remains unchanged for the GC samples and the effective linewidth slightly increases with the time of heat treatment. 
This behaviour, together with the lower radiative transition probability for the ${ }^{4} \mathrm{~F}_{3 / 2} \rightarrow{ }^{4} \mathrm{I}_{11 / 2}$ emission for the crystallised samples, leads to smaller stimulated emission cross-sections for the GC samples, in the range of values found in silicate glasses (0.9$\left.3.6 \mathrm{pm}^{2}\right)[24]$.

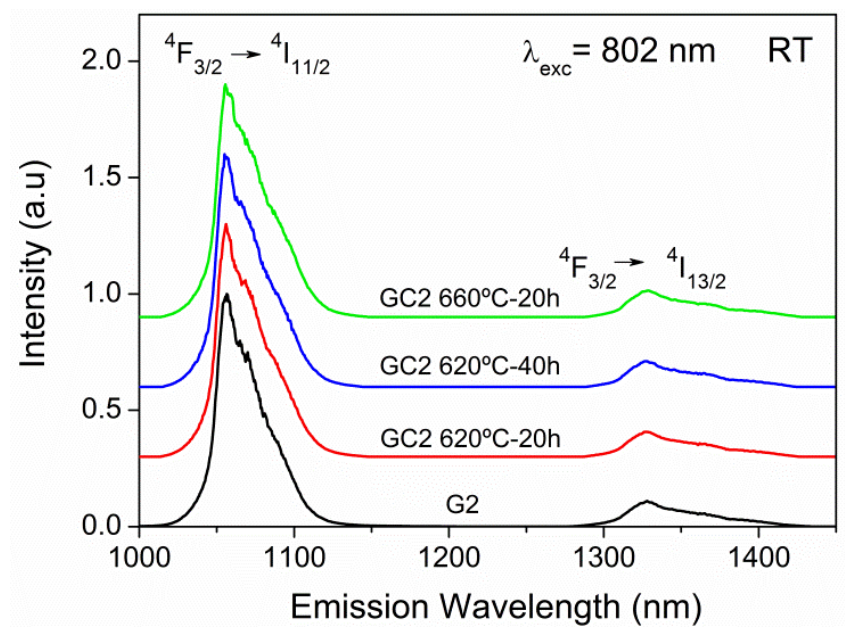

Fig. 6. Room-temperature emission spectra of the ${ }^{4} \mathrm{~F}_{3 / 2} \rightarrow{ }^{4} \mathrm{I}_{1 / 2,13 / 2}$ transitions of $\mathrm{Nd}^{3+}$ ions (2 mol\%) obtained under excitation at $802 \mathrm{~nm}$.

Table 2. Room-temperature emission properties of $\mathrm{Nd}(2 \mathrm{~mol} \%)$ in the glass and glass-ceramic.

\begin{tabular}{llllll}
\hline Sample & $\mathrm{n}$ & $\lambda_{\mathrm{p}}(\mathrm{nm})$ & $\Delta \lambda_{\text {eff }}(\mathrm{nm})$ & $\sigma_{\mathrm{p}}\left(\mathrm{pm}^{2}\right)$ & $\tau_{\mathrm{R}}(\mu \mathrm{s})$ \\
\hline Glass & 1.523 & 1057 & 35.95 & 2.8 & 345 \\
\hline $\mathrm{GC} 2-620^{\circ} \mathrm{C}-20 \mathrm{~h}$ & 1.525 & 1057 & 37.16 & 2.4 & 390 \\
\hline $\mathrm{GC} 2-620^{\circ} \mathrm{C}-40 \mathrm{~h}$ & 1.526 & 1057 & 37.60 & 2.3 & 395 \\
\hline $\mathrm{GC} 2-660^{\circ} \mathrm{C}-20 \mathrm{~h}$ & 1.526 & 1057 & 38.94 & 2.2 & 398 \\
\hline
\end{tabular}

The steady-state emission spectra exhibit similar spectral features for all concentrations and heat treatments. However, the excitation spectra of the GC samples doped with 0.1, 0.2 , and $0.5 \mathrm{~mol} \%$ performed in the spectral range $765-910 \mathrm{~nm}$ monitored at $1057 \mathrm{~nm}$ show a fine structure superimposed on the broad ${ }^{4} \mathrm{I}_{9 / 2} \rightarrow{ }^{4} \mathrm{~F}_{5 / 2,3 / 2}$ bands of the glass, confirming the partial incorporation of $\mathrm{Nd}^{3+}$ ions in the nanocrystals. In the samples doped with 1 and $2 \mathrm{~mol} \%, \mathrm{Nd}^{3+}$ ions are responsible for the main contribution to the spectra in the amorphous environment. As an example, Fig. 7 shows the excitation spectra for the samples doped with 0.1 and $1 \mathrm{~mol} \%$ where better resolved peaks are observed for the lower $\mathrm{Nd}^{3+}$ concentration. 

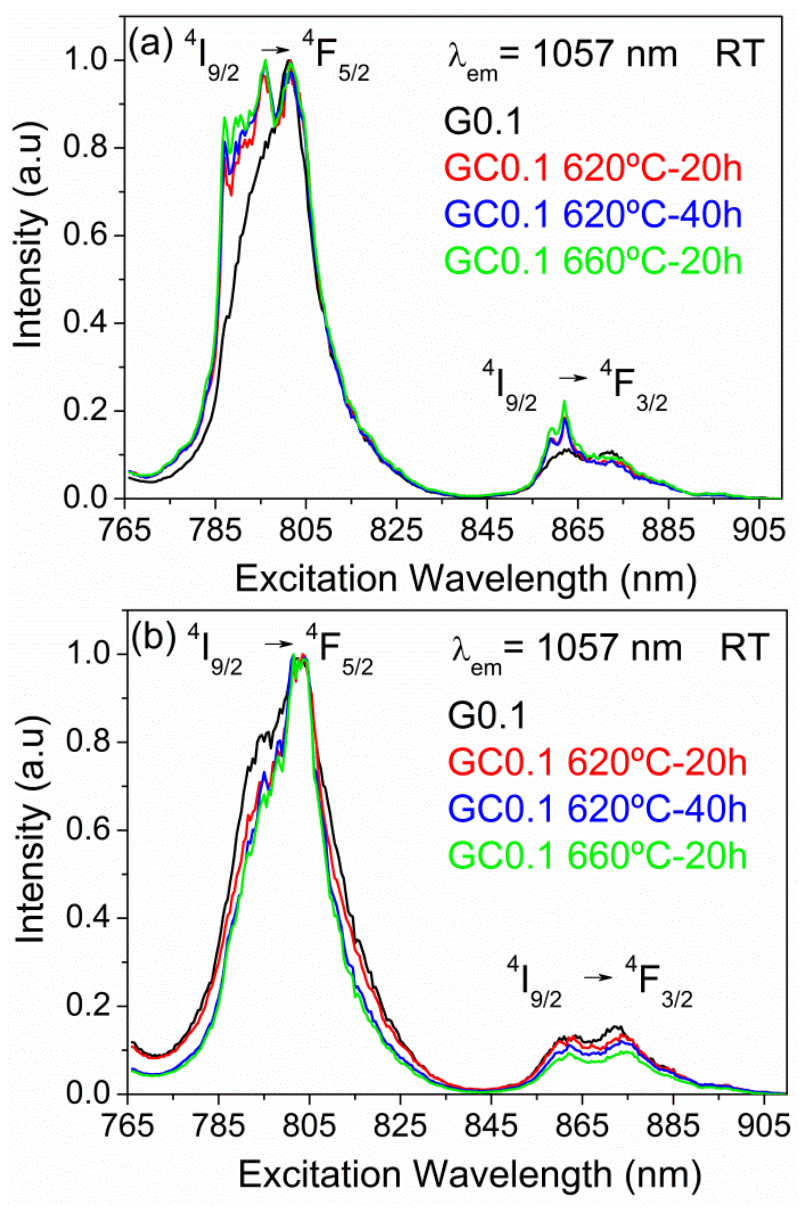

Fig. 7. Room temperature excitation spectra of the ${ }^{4} \mathrm{I}_{9 / 2} \rightarrow{ }^{4} \mathrm{~F}_{5 / 2,3 / 2}$ transitions of $\mathrm{Nd}^{3+}$ obtained by collecting the luminescence at $1057 \mathrm{~nm}$ for the samples doped with (a) $0.1 \mathrm{~mol} \% \mathrm{NdF}_{3}$ and (b) $1 \% \mathrm{Nd}$.

The decays of the ${ }^{4} \mathrm{~F}_{3 / 2}$ state were obtained by exciting with a pulsed Ti:sapphire laser at $802 \mathrm{~nm}$ in the ${ }^{4} \mathrm{I}_{9 / 2} \rightarrow{ }^{4} \mathrm{~F}_{5 / 2}$ absorption band at $295 \mathrm{~K}$. Fig. 8 shows the logarithmic plot of the experimental decays of the ${ }^{4} \mathrm{~F}_{3 / 2}$ level for the samples doped with 0.1 and $1 \mathrm{~mol} \%$ of $\mathrm{NdF}_{3}$ at room temperature. The decays of the samples doped with $0.1 \mathrm{~mol} \%$ may be described to a good approximation by a single exponential function, whereas the decays of the samples doped with $1 \mathrm{~mol} \%$ deviate from a single exponential and the lifetime decreases.

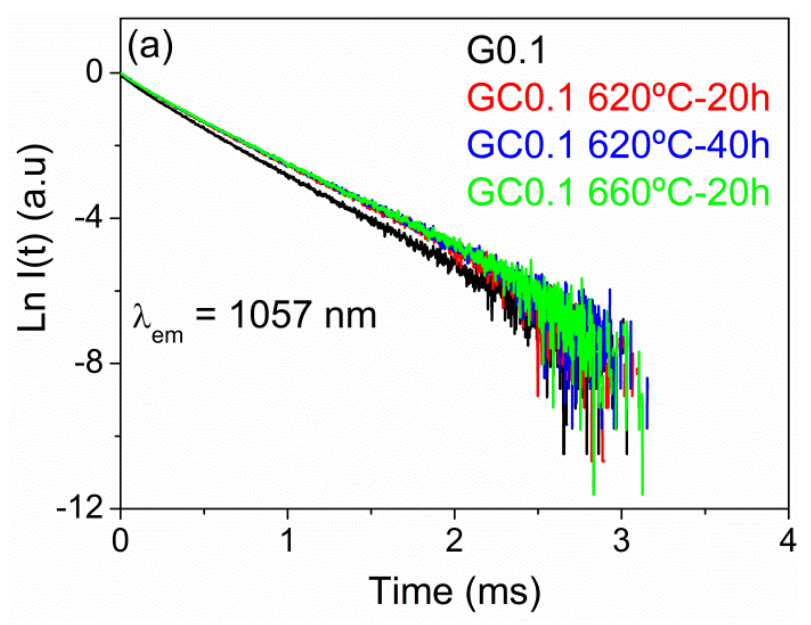




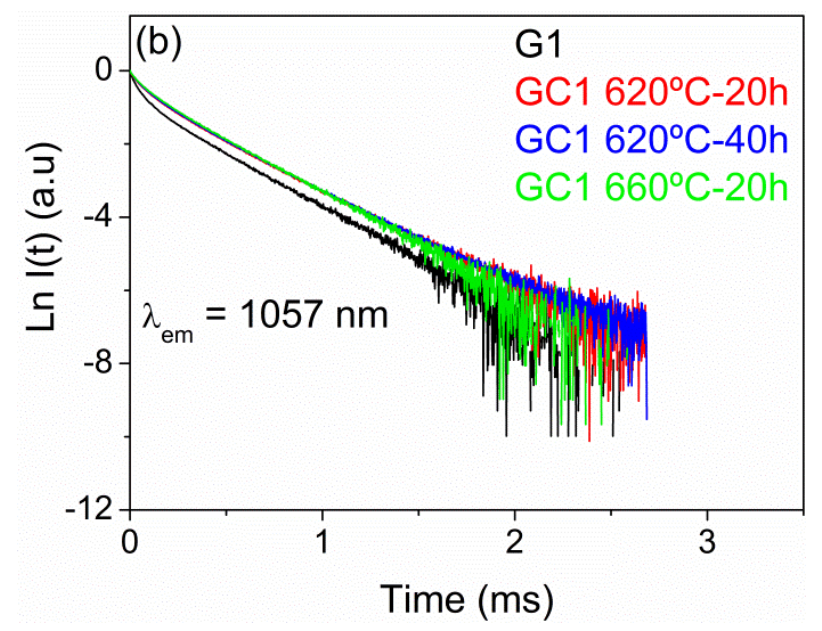

Fig. 8. Logarithmic plot of the room temperature experimental decays from the ${ }^{4} \mathrm{~F}_{3 / 2}$ state for the samples doped with (a) 0.1 and (b) 1 mol\% of $\mathrm{NdF}_{3}$. The decays were obtained by exciting at ${ }^{4} \mathrm{I}_{9 / 2} \rightarrow{ }^{4} \mathrm{~F}_{5 / 2}$ transition and monitored at $1057 \mathrm{~nm}$.

Table 3 lists the lifetime values for all the samples. The lifetime values for the samples with concentrations higher than $0.1 \mathrm{~mol} \%$ correspond to the average lifetime defined by:

$$
\langle\tau\rangle=\frac{\int I(t) d t}{I_{0}}
$$

where $I(t)$ is the intensity at time t. According to these radiative lifetimes, the quantum efficiencies $\left(\eta=\tau_{\text {exp }} / \tau_{R}\right)$ are around 99 and $41 \%$ for the glass samples doped with 0.1 and $2 \mathrm{~mol} \%$, respectively. This strong reduction of the quantum efficiency for increasing $\mathrm{Nd}$ concentration indicates the presence of non-radiative cross-relaxation processes such as $\left({ }^{4} \mathrm{~F}_{3 / 2},{ }^{4} \mathrm{I}_{9 / 2}\right) \rightarrow\left({ }^{4} \mathrm{I}_{15 / 2},{ }^{4} \mathrm{I}_{15 / 2}\right)$. The lifetime of the GC samples is longer than those of glass samples for all the concentrations, which suggests a fluoride environment for $\mathrm{Nd}^{3+}$ ions according to their incorporation in the nanocrystals. The results are similar for the three heat treatments which indicate that after $20 \mathrm{~h}$ at $620{ }^{\circ} \mathrm{C}$, the rare-earth ions are largely incorporated into a crystalline environment.

Table 3. Experimental lifetimes of the ${ }^{4} \mathrm{~F}_{3 / 2}$ level obtained under excitation at $802 \mathrm{~nm}$ by collecting the luminescence at $1057 \mathrm{~nm}$ as a function of $\mathrm{Nd}^{3+}$ concentration and heat treatment. The radiative lifetime is shown in the last column.

\begin{tabular}{lcccccc}
\hline Sample & $\mathbf{0 . 1 \%}$ & $\mathbf{0 . 2 \%}$ & $\mathbf{0 . 5 \%}$ & $\mathbf{1 \%}$ & $\mathbf{2 \%}$ & $\boldsymbol{\tau}_{\mathbf{R}}(\boldsymbol{\mu} \mathbf{s})$ \\
\hline Glass & 343 & 298 & 268 & 192 & 143 & 345 \\
\hline GC2-620 ${ }^{\circ} \mathrm{C}-20 \mathrm{~h}$ & 382 & 350 & 308 & 251 & 187 & 390 \\
\hline GC2-620 & & & & & & \\
\hline GC2-40h & 385 & 354 & 310 & 254 & 191 & 395 \\
\hline
\end{tabular}




\subsection{Site-selective spectroscopy}

To obtain further information about the different environments for $\mathrm{Nd}^{3+}$ ions in the glassceramics, emission spectra were performed by exciting at different wavelengths along the ${ }^{4} \mathrm{I}_{9 / 2} \rightarrow{ }^{4} \mathrm{~F}_{5 / 2}$ absorption band. Fig. 9(a) shows the emission spectra obtained by exciting at 786 and $802 \mathrm{~nm}$ for the GC samples doped with $0.1 \mathrm{~mol} \%$ of $\mathrm{Nd}^{3+}$ treated at $620{ }^{\circ} \mathrm{C}$ $40 \mathrm{~h}$. The figure reveals the strong difference between spectra of differing excitation wavelength, which indicates that $\mathrm{Nd}^{3+}$ ions are in different crystal-field sites. The spectrum obtained at $786 \mathrm{~nm}$ shows a more resolved structure, indicating a crystalline environment for the $\mathrm{Nd}^{3+}$ ions. In contrast, that obtained under excitation at $802 \mathrm{~nm}$ shows a more inhomogeneous broadened band similar to that of the glass sample. Moreover, the excitation spectra obtained by collecting the luminescence at 1039 and $1057 \mathrm{~nm}$ also reveal the presence of different environments for $\mathrm{Nd}^{3+}$ ions. Fig. 9(b) shows the excitation spectra for the same sample doped with $0.1 \mathrm{~mol} \%$ of $\mathrm{Nd}^{3+}$. The spectrum monitored at $1039 \mathrm{~nm}$ presents narrower and well-resolved peaks corresponding to $\mathrm{Nd}^{3+}$ ions in the nanocrystals. As concentration increases, the spectra become broader and less resolved.

To clearly identify emission from $\mathrm{Nd}^{3+}$ in the nanocrystals, the emission and excitation spectra were measured at low temperature, thereby minimising the overlapping of contributions from $\mathrm{Nd}^{3+}$ in the crystalline and amorphous phases due to the lower thermal population of the higher energy Stark components of the ground and excited states. The low-temperature $(9 \mathrm{~K})$ excitation spectra are presented in Fig. 10 for the GC samples doped with 0.1 and $1 \mathrm{~mol} \%$. As observed in the spectra obtained at $1039 \mathrm{~nm}$, the low-energy band corresponding to the ${ }^{4} \mathrm{I}_{9 / 2} \rightarrow{ }^{4} \mathrm{~F}_{3 / 2}$ doublet narrows and divides into two single components, as expected for a well-defined crystal-field site. Moreover, the ${ }^{4} \mathrm{I}_{9 / 2} \rightarrow{ }^{4} \mathrm{~F}_{5 / 2}$ band is composed of narrow and well-resolved peaks which indicate that the spectra obtained at $1039 \mathrm{~nm}$ correspond to $\mathrm{Nd}^{3+}$ ions in the $\mathrm{LaF}_{3}$ nanocrystals. Conversely, the spectra obtained at $1057 \mathrm{~nm}$ show broad bands similar to those found in the glass samples.
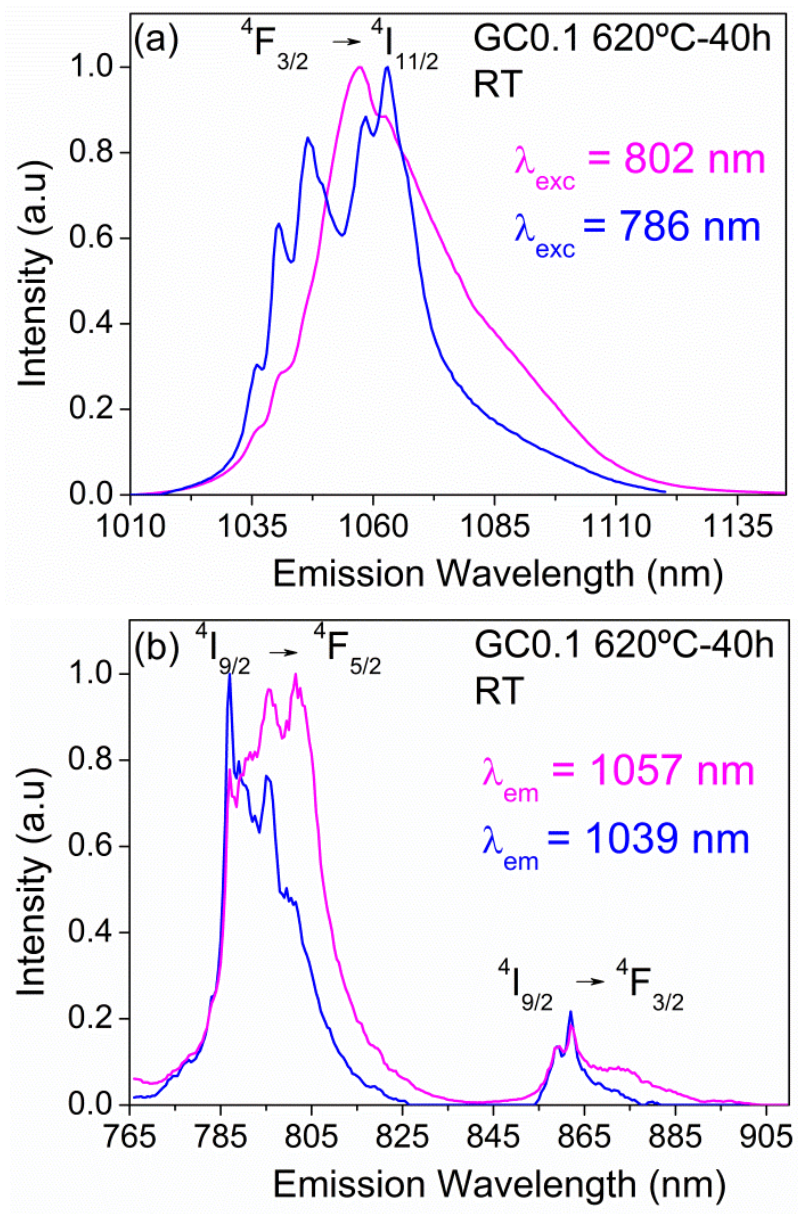
Fig. 9. (a) Room-temperature emission spectra obtained under excitation at 786 and $802 \mathrm{~nm}$ for the GC1 sample doped with $0.1 \mathrm{~mol} \%$; (b) excitation spectra obtained on collecting the luminescence at 1039 and $1057 \mathrm{~nm}$ for the $\mathrm{GC}$ treated at $620^{\circ} \mathrm{C}-40 \mathrm{~h}$ sample doped with $0.1 \mathrm{~mol} \%$.
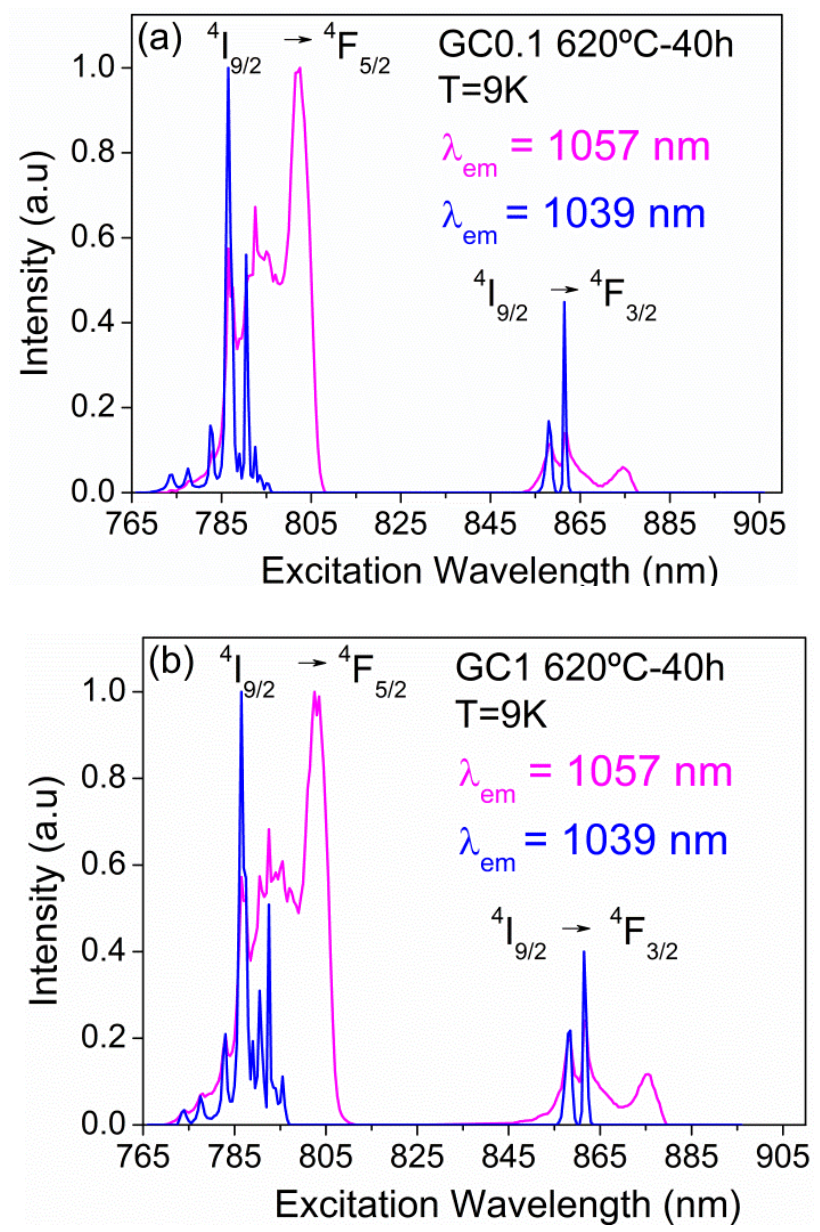

Fig. 10. Low-temperature excitation spectra obtained on collecting the luminescence at 1039 and 1057 $\mathrm{nm}$ for the GC samples doped with (a) 0.1 and (b) $1 \mathrm{~mol} \%$.

In order to confirm if the features shown by the excitation spectra monitored at $1039 \mathrm{~nm}$ can be unambiguously related to the $\mathrm{Nd}^{3+}$ ions in the nanocrystals, site-selective steady-state emission spectra for the ${ }^{4} \mathrm{~F}_{3 / 2} \rightarrow{ }^{4} \mathrm{I}_{11 / 2}$ transition were recorded by exciting at 786 and $802 \mathrm{~nm}$. Fig. 11 shows the normalized emission spectra at $9 \mathrm{~K}$ obtained under excitation at 786 and $802 \mathrm{~nm}$ for the GC samples doped with 0.1 and $1 \mathrm{~mol} \%$, showing quite different emission spectra depending on the excitation wavelength. The spectrum obtained under excitation at $786 \mathrm{~nm}$ shows sharp peaks, one at $1039 \mathrm{~nm}$ which does not overlap with the emission spectrum obtained by exciting at $802 \mathrm{~nm}$. In the latter, the sharp peaks disappear and the spectrum becomes broader and similar to that found in the glass sample. These results indicate that in the glassceramic samples excited at $786 \mathrm{~nm}, \mathrm{Nd}^{3+}$ ions mainly reside in the crystalline phase. As concentration increases, the emission from $\mathrm{Nd}^{3+}$ ions in the nanocrystals decreases, and the spectra become broader with more poorly resolved peaks. Similar emission spectra are obtained by exciting the ${ }^{4} \mathrm{I}_{9 / 2} \rightarrow{ }^{4} \mathrm{~F}_{3 / 2}$ band at 861.5 and $876 \mathrm{~nm}$.

Furthermore, the existence of different environments for the $\mathrm{Nd}^{3+}$ ions in the $\mathrm{LaF}_{3}$ nanocrystals is also reflected in the lifetimes of the ${ }^{4} \mathrm{~F}_{3 / 2}$ state, the values of which should depend on the excitation and emission wavelengths. Lifetime measurements of the ${ }^{4} \mathrm{~F}_{3 / 2}$ state were performed by exciting the samples at 786 and $802 \mathrm{~nm}$, and collecting the luminescence at 1039 and 1057 
$\mathrm{nm}$, respectively (Fig. 12). Under excitation at $786 \mathrm{~nm}$ and collecting the luminescence at 1039 $\mathrm{nm}$, the decay is a single exponential with a lifetime of $688 \mu$ s for the GC sample doped with $0.1 \%$, whereas by exciting at $802 \mathrm{~nm}$ and collecting the luminescence at $1057 \mathrm{~nm}$, the lifetime is $336 \mu$ s (Table 4). The longer lifetimes corresponds to the $\mathrm{Nd}^{3+}$ ions incorporated in the nanocrystals. This lifetime is highly dependent on Nd concentration, decreasing to $98 \mu$ s for the GC samples doped with $1 \mathrm{~mol} \%$.
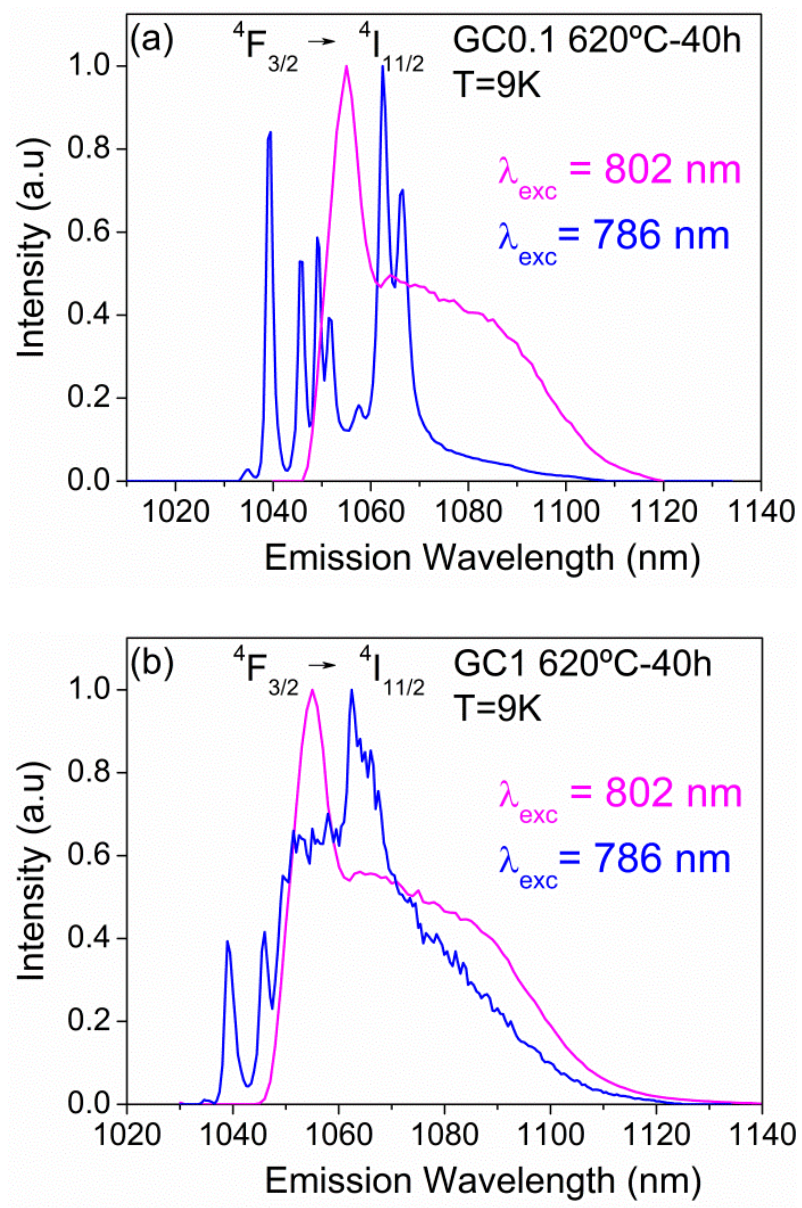

Fig. 11. Low temperature emission spectra obtained under excitation at 786 and $802 \mathrm{~nm}$ for the GC samples doped with (a) 0.1 and (b) 1 mol\%.

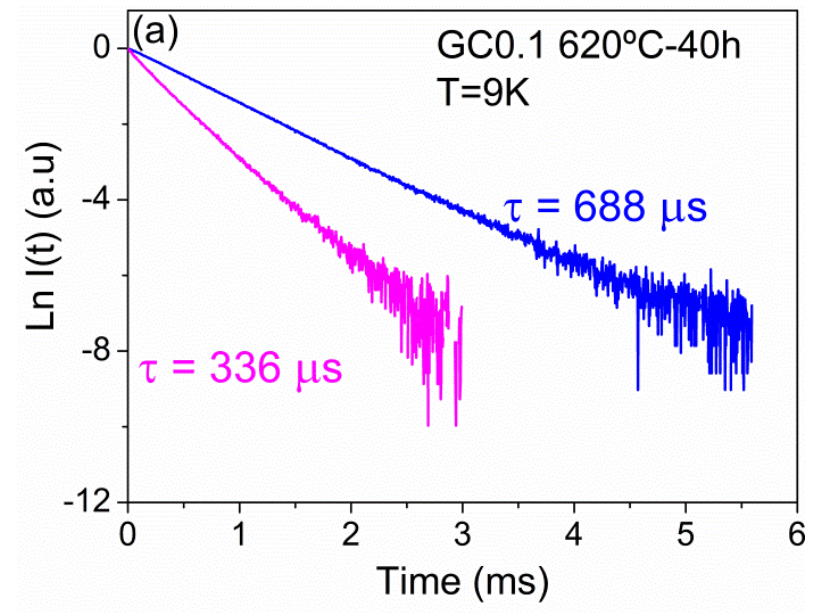




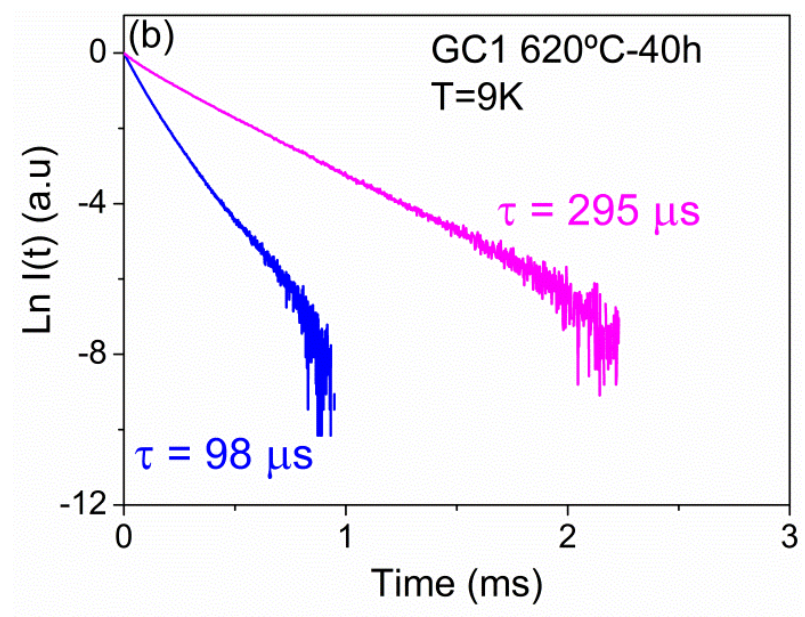

Fig. 12. Logarithmic plot of the experimental decays from the ${ }^{4} \mathrm{~F}_{3 / 2}$ state obtained under excitation at 786 $\mathrm{nm}$ (blue lines) and $802 \mathrm{~nm}$ (pink lines) for the GC samples doped with (a) 0.1 and (b) $1 \mathrm{~mol} \%$.

Table 4. Experimental lifetimes, at low temperature, of the ${ }^{4} \mathrm{~F}_{3 / 2}$ level obtained under excitation at 790 and $802 \mathrm{~nm}$ collecting the luminescence at 1039 and $1057 \mathrm{~nm}$, respectively.

\begin{tabular}{ccc}
\hline \% Nd & $\boldsymbol{\lambda}_{\text {exc }}=\mathbf{7 8 6} \mathbf{~ n m}$ & $\boldsymbol{\lambda}_{\text {exc }}=\mathbf{8 0 2} \mathbf{~ n m}$ \\
\hline 0.1 & $\tau_{\text {exp }}(\mu \mathrm{s})$ & $\tau_{\text {exp }}(\mu \mathrm{s})$ \\
\hline 0.2 & 688 & 336 \\
\hline 0.5 & 462 & 337 \\
\hline 1 & 188 & 332 \\
\hline 2 & 98 & 295 \\
\hline
\end{tabular}

As observed, there is a strong quenching of the lifetimes of $\mathrm{Nd}^{3+}$ in the $\mathrm{LaF}_{3}$ nanocrystals, but much less so in the amorphous phase. This behaviour is likely explained from the considerable diffusion of $\mathrm{Nd}^{3+}$ ions from the glass matrix to the $\mathrm{LaF}_{3}$ nanocrystals, as confirmed in the same system doped with $\mathrm{Tm}^{3+}$ studied by XANES [23]. In this previous work, the ionization energy $\mathrm{E}_{0}$ of $\mathrm{Tm}^{3+}$, calculated from the derivate function of the XANES spectra, increased during the crystallisation process, from the glass to the glass-ceramic. It was concluded; therefore, that part of the RE ions existed in a fluorine-rich environment, since the electronegativity of fluorine is higher than that of oxygen. Additionally, the decrease in FWHM of the $\mathrm{Tm}^{3+}$ absorption-edge peak from the glass to the glass-ceramic indicated a higher symmetry and, correspondingly, crystallinity of the $\mathrm{Tm}^{3+}$ environment in the glass-ceramics. Thus, an increase of the crystalline fraction with the heat treatment time at $620{ }^{\circ} \mathrm{C}$, from 10 to $40 \mathrm{~h}$, was concluded to occur simultaneously with the diffusion process, resulting in the incorporation of around $30 \% \mathrm{of} \mathrm{Tm}^{3+}$ in the $\mathrm{LaF}_{3}$ crystalline structure after $40 \mathrm{~h}$. Starting from the crystalline fractions obtained by Rietveld refinement, the ratio of the concentration of $\mathrm{Tm}^{3+}$ in the crystalline phase to that in the 
glass matrix was calculated (with an error of $\sim 25 \%$ ), to be approximately 12 for treatment times of $40 \mathrm{~h}$.

In the present work, the same composition is used doping with $\mathrm{Nd}^{3+}$. The GCs were obtained in similar conditions and the crystalline fractions calculated from Rietveld analysis are in close agreement with those obtained in the previous work [23]. In the present case, the crystalline fraction depends on the $\mathrm{Nd}$ content.

As discussed previously, for treatment times of $40 \mathrm{~h}$, the diffusion process should be essentially complete, as indicated by the constant crystal size for treatments of $20 \mathrm{~h}$ and longer. If a silicarich diffusion barrier is established, no further $\mathrm{Nd}^{3+}$ diffusion will take place and so it is possible to consider that around $30 \%$ of the $\mathrm{Nd}^{3+}$ ions will be in the crystalline phase. Using the same method followed in [23], the respective $\mathrm{Nd}^{3+}$ contents in the amorphous and crystalline phases were calculated, with an error $\sim 25 \%$, and are shown in Table 5.

Table 5. Crystal fraction in wt $\%$ of glasses treated at $640{ }^{\circ} \mathrm{C}-40 \mathrm{~h}$ with different $\mathrm{Nd}^{3+}$ contents, along with the respective concentration of $\mathrm{Nd}^{3+}$ in the glass matrix and $\mathrm{LaF}_{3} \mathrm{NCs}$.

\begin{tabular}{llll}
\hline \% Nd & wt \% crystallisation & \% Nd in glass & \% Nd in NCs \\
\hline 0.1 & 6.4 & 0.076 & 1.2 \\
\hline 1 & 8.8 & 0.65 & 8.58 \\
\hline 2 & 8.2 & 1.3 & 17.16 \\
\hline
\end{tabular}

The relative concentrations of $\mathrm{Nd}^{3+}$ in the glass matrix and $\mathrm{LaF}_{3}$ nanocrystals could explain the strong quenching of the $\mathrm{Nd}^{3+}$ emission for $\mathrm{Nd}^{3+}$ contents higher than $0.1 \%$, whereas in the glass matrix no significant quenching is observed. Further work is in progress to confirm these calculations by measuring all the samples by XAS-XANES.

\section{Conclusions}

The crystallisation mechanism of transparent glass-ceramics in the system $55 \mathrm{Si}-10 \mathrm{La}$ doped with increasing $\mathrm{Nd}^{3+}$ concentrations was confirmed as a diffusion-controlled process starting from a constant number of nuclei already present in the initial glass. The addition of $\mathrm{Nd}^{3+}$ increases the $\mathrm{Tg}$ of the glasses and appears to affect the crystallisation kinetics. As the $\mathrm{Nd}^{3+}$ content increases, the crystallised fraction also increases indicating that $\mathrm{Nd}^{3+}$ ions likely play a role as nucleating agent. Nevertheless, smaller crystals are obtained for the higher $\mathrm{Nd}^{3+}$ content. TEM and SAXS techniques have provided complementary information about the size and distribution of phase separation droplets and nanocrystals in the base glass and their evolution in the corresponding glassceramics.

Preferential incorporation of $\mathrm{Nd}^{3+}$ in the crystalline phase was confirmed by HR-TEMEDX and several types of optical property measurement. These include splitting of the absorption and emission bands together with reduction of the $\Omega_{2}$ parameter in the glassceramic samples as compared to the glass samples and site-selective spectroscopy obtained under excitation of the ${ }^{4} \mathrm{I}_{9 / 2} \rightarrow{ }^{4} \mathrm{~F}_{3 / 2} /{ }^{4} \mathrm{~F}_{5 / 2}$ transitions.

Low-temperature site-selective emission and excitation spectra together with different lifetime values of the ${ }^{4} \mathrm{~F}_{3 / 2}$ state depending on the excitation and emission wavelengths allow emission from $\mathrm{Nd}^{3+}$ ions in the $\mathrm{LaF}_{3}$ nanocrystals to be isolated and, in turn, correlation of the spectroscopic and structural properties. The optimum amount of dopant corresponds to $0.1 \mathrm{~mol} \%$; strong quenching of the lifetime of $\mathrm{Nd}^{3+}$ in the $\mathrm{LaF}_{3}$ nanocrystals occurs for higher concentrations. 


\section{Acknowledgements}

This work was supported by the Spanish Government MINECO under Projects No. MAT2013-48246-C2-1-P and MAT2013-48246-C2-2-P and Basque Country Government IT-943-16. J.J. Velázquez also acknowledges the Spanish Government MINECO under Grant FPDI-2013-16895. G.C. acknowledges U.S. National Science Foundation for partial support under Grant \# DMR-1507670. The authors wish to thank L. Pascual from ICP (CSIC) for her support in the TEM studies. 


\section{References}

[1] G. Blasse and B. C. Grabmaier, Luminescent Materials, Springer, New York, 1994.

[2] E. Downing, L. Hesselink, J. Ralston and R. Macfarlane, A Three-Color, Solid-State, Three-Dimensional Display, Science 273 (1996) 1185-1189.

DOI: $10.1126 /$ science.273.5279.1185

[3] E. Desurvire, Erbium-Doped Fiber Amplifiers: Principles and Applications, Wiley, New York, 1994.

[4] F. Wang, Y. Han, C. S. Lim, Y. Lu, J. Wang, J. Xu, H. Chen, C. Zhang,M. Hong, and $\mathrm{X}$. Liu, Simultaneous phase and size control of upconversion nanocrystals through lanthanide doping, Nature, 463 (2010) 1061-1065.

DOI:10.1038/nature08777

[5] X. Huang, S. Han, W. Huang, and X. Liu, Enhancing solar cell efficiency: the search for luminescent materials as spectral converters, Chem. Soc. Rev. 42 (2013) 173-201.

DOI: $10.1039 / \mathrm{C} 2 \mathrm{CS} 35288 \mathrm{E}$

[6] A. de Pablos-Martin, M. Ferrari, M.J. Pascual and G.C. Righini, Glass-ceramics: a class of nanostructured materials for photonics, Rivista del Nuovo Cimento, 38 (2015) 311-369. DOI: $10.1393 / \mathrm{ncr} / \mathrm{i} 2015-10114-0$

[7] Y. Wang and J. Ohwaki, New transparent vitroceramics codoped with $\mathrm{Er}^{3+}$ and $\mathrm{Yb}^{3+}$ for efficient frequency upconversion, Appl. Phys. Lett. 63 (1993) 3268-3270.

DOI: $10.1063 / 1.110170$

[8] A. de Pablos-Martín, A. Durán and M.J. Pascual, Nanocrystallisation in oxyfluoride systems: mechanisms of crystallisation and photonic properties, Int. Mater. Rev. 57 (2012) $165-186$.

DOI: $10.1179 / 1743280411 Y .0000000004$

[9] P.P. Fedorov, A.A. Luginina and A.I. Popov, Transparent oxyfluoride glass ceramics, J. Fluorine Chem. $172(2015)$ 22-50.

DOI: $10.1016 /$ j.jfluchem.2015.01.009

[10] M. Sroda, I. Waclawska, L. Stoch and M. Reben, DTA/DSC study of nanocrystallization in oxyfluoride glasses, J. Therm. Anal. Calorim. 77 (2004) 193-200.

DOI: 10.1023/B:JTAN.0000033203.95251.d6

[11] S. Tanabe, H. Hayashi, T. Hanada and N. Onodera,

Fluorescence properties of $\mathrm{Er}^{3+}$ ions in glass ceramics containing $\mathrm{LaF}_{3}$ nanocrystals, Opt. Mater. 19 (2002) 343-349.

DOI: $10.1016 / \mathrm{S} 0925-3467(01) 00236-1$

[12] Z. Hu, E. Ma, Y. Wang and D. Chen, Fluorescence property investigations on $\mathrm{Er}^{3+}-$ doped oxyfluoride glass ceramics containing $\mathrm{LaF}_{3}$ nanocrystals, Mater. Chem. Phys. 100 (2006) 308-312.

DOI: $10.1016 /$ j.matchemphys.2006.01.015

[13] E. Ma, Z. Hu, Y. Wang and F. Bao, J. Lumin., Influence of structural evolution on fluorescence properties of transparent glass ceramics containing $\mathrm{LaF}_{3}$ nanocrystals, 118 (2006) 131-138.

DOI: $10.1016 /$ j.jlumin.2005.08.004

[14] F. Goutaland, P. Jander, W.S. Brocklesby and G.J. Dai, Crystallisation effects on rare earth dopants in oxyfluoride glass ceramics, Opt. Mater. 22 (2003) 383-390.

DOI: $10.1016 /$ S0925-3467(02)00373-7

[15] A. Sarakovskis, J. Grube, G. Doke and M. Springis, Excited state absorption and energy-transfer mechanisms of up-conversion luminescence in $\mathrm{Er}^{3+}$-doped oxyfluoride glass ceramics at different temperatures, J. Lumin. 130 (2010) 805-811. DOI:10.1016/j.jlumin.2009.11.037

[16] Wei, J.J. Li, J.W. Yang, X.N. Chi and H. Guo, Enhanced green upconversion in $\mathrm{Tb}^{3+}-$ $\mathrm{Yb}^{3+}$ co-doped oxyfluoride glass ceramics containing $\mathrm{LaF}_{3}$ nanocrystalsJ. Lumin. 137 (2013) 70-72.

DOI: $10.1016 /$ j.jlumin.2012.11.017 
[17] A. de Pablos-Martín, D. Ristic, S. Bhattacharyya, T. Höche, G. C. Mather, M.O. Ramírez, S. Soria, M. Ferrari, G. C. Righini, L.E. Bausá, A. Durán and M.J. Pascual, Effects of $\mathrm{Tm}^{3+}$ additions on the crystallization of $\mathrm{LaF}_{3}$ nanocrystals in oxyfluoride glasses: Optical characterization and up-conversion, J. Am. Ceram. Soc. 96 (2013) 447-457.

DOI:10.1111/jace.12120

[18] S. Ye, B. Zhu, J. Luo, J. Chen, G. Lakshminarayana and J. Qiu, Enhanced cooperative quantum cutting in $\mathrm{Tm}^{3+}-\mathrm{Yb}^{3+}$ codoped glass ceramics containing $\mathrm{LaF}_{3}$ nanocrystals, Opt. Express 16 (2008) 8989-8994.

DOI: $10.1364 / \mathrm{OE} .16 .008989$

[19] Y. Yu, D. Chen, E. Ma, Y. Wang and Z. Hu,

Spectroscopic properties of $\mathrm{Nd}^{3+}$ doped transparent oxyfluoride glass ceramics, Spectrochim. Acta A 67 (2007) 709-713.

[20] W.J. Zhang, Q.J. Chen, Q.Y. Zhang and Z.H. Jiang, J. Non-Cryst. Solids, 2011, 357, $2278-2281$.

[21] N. Hémono, G. Pierre, F. Muñoz, A. de Pablos-Martín, M.J. Pascual, A. Durán, Processing of transparent glass-ceramics by nanocrystallisation of $\mathrm{LaF}_{3}$, J. Eur. Ceram. Soc. 29 (2009) 2915-2920.

DOI: 10.1016/j.jeurceramsoc.2009.05.013

[22] A. de Pablos-Martín, N. Hémono, G.C. Mather, S. Bhattacharyya, T. Höche, H. Bornhöft, J. Deubener, F. Muñoz, A Durán and M.J. Pascual, Effects of Tm ${ }^{3+}$ additions on the crystallization of $\mathrm{LaF}_{3}$ nanocrystals in oxyfluoride glasses: optical characterization and up-conversion, J. Am. Ceram. Soc. 94 (2011) 2420-2428.

DOI: $10.1111 /$ jace. 12120

[23] A. de Pablos-Martín, M.A. García, A. Muñoz-Noval, G.R. Castro, M.J. Pascual and A. Durán, Analysis of the distribution of $\mathrm{Tm}^{3+}$ ions in $\mathrm{LaF}_{3}$ containing transparent glassceramics through X-ray absorption spectroscopy, J. Non-Crystal. Solids 384 (2014) 83-87. DOI: $10.1016 /$ j.jnoncrysol.2013.07.021

[24] M. J. Weber, Science and technology of laser glass, J. Non-Cryst. Solids 123 (1990) 208-222.

DOI: 10.1016/0022-3093(90)90786-L

[25] R.R. Jacobs and M.J. Weber, Dependence of the ${ }^{4} \mathrm{~F}_{3 / 2} \rightarrow{ }^{4} \mathrm{I}_{11 / 2}$ induced-emission cross section for $\mathrm{Nd}^{3+}$ on glass composition, IEEE J. Quantum Electron. QE-12 (1976) 102-111. DOI: 10.1109/JQE.1976.1069101

[26] V. Lavín, I. Iparraguirre, J. Azkargorta, A. Mendioroz, A. Gonzalez-Platas, R. Balda, and J. Fernández, Opt. Mater., 2004, 25(2), 201-208.

DOI: 10.1016/S0925-3467(03)00270-2

[27] F. Lahoz, I.R. Martín, U.R. Rodríguez Mendoza, I. Iparraguirre, J. Azkargorta, A. Mendioroz, R. Balda, J. Fernández and V. Lavín, Rare earths in nanocrystalline glass ceramics, Opt. Mater. 27 (2005) 1762-1770.

DOI: $10.1016 /$ j.optmat.2004.11.047

[28] J. Pisarska, W. Ryba-Romanowski, G. Dominiak-Dzik, T. Goryczka and W.A. Pisarski, Nd-doped oxyfluoroborate glasses and glass-ceramics for NIR laser applications, J. Alloy Compd. 451 (2008) 223-225.

DOI:10.1016/j.jallcom.2007.04.167

[29] J. Pisarska W. Ryba-Romanowski, G. Dominiak-Dzik, T. Goryczka and W.A.Pisarski, Near-infrared luminescence of rare earth ions in oxyfluoride lead borate glasses and transparent glass-ceramic materials, Opt Appl. 38 (2008) 211-216.

[30] M. Abril, J. Mendez-Ramos, I.R. Martin, U.R. Rodriguez-Mendoza, V. Lavin, A. Delgado-Torres, V.D. Rodriguez, P. Nunez and A.D. Lozano-Gorrin, Optical properties of $\mathrm{Nd}^{39}$ ions in oxyfluoride glasses and glass ceramics comparing different preparation methods, J. Appl Phys. 95 (2004) 5271-5279.

DOI: $10.1063 / 1.1707204$

[31] J. Mendez-Ramos, M. Abril, I.R. Martin, U.R. Rodriguez-Mendoza, V. Lavin, V. D. Rodriguez, P. Nunez and A. D. Lozano-Gorrin, Ultraviolet and visible upconversion 
luminescence in $\mathrm{Nd}^{3+}$-doped oxyfluoride glasses and glass ceramics obtained by different preparation methods, J. Appl Phys. 99 (2006) 113510(1-5).

DOI: $10.1063 / 1.2203395$

[32] D. Chen, Y. Wang, Y. Yu and Z. Hu, Crystallization and fluorescence properties of $\mathrm{Nd}^{3+}$-doped transparent oxyfluoride glass ceramics, Mater. Sci. Eng. B 123 (2005) 1-6.

DOI: $10.1016 /$ j.mseb.2005.06.008

[33] Y. Yu, D. Chen, Y. Cheng Y, Y.. Wang, Z. Hu and F. Bao, Investigation on crystallization and influence of $\mathrm{Nd}^{3+}$ doping of transparent oxyfluoride glass-ceramics, J. Eur Ceram Soc. 26 (2006) 2761-2767.

DOI: $10.1016 /$ j.jeurceramsoc.2005.05.002

[34] F. Liu , Y. Wang, D. Chen and Y. L. Yu, Investigation on crystallization kinetics and microstructure of novel transparent glass ceramics containing $\mathrm{Nd}: \mathrm{NaYF}_{4}$ nano-crystals, Mater. Sci. Eng. B $136(2007) 106-110$.

DOI: $10.1016 /$ j.mseb.2006.09.012

[35] D. Chen, Y.S. Wang, E. Ma, Y. Yu, F. Liu and R.F. Li, Spectroscopic and stimulated emission characteristics of $\mathrm{Nd}^{3+}$ in transparent glass ceramic embedding $\beta-\mathrm{YF}_{3}$ nanocrystals, J. Appl. Phys. 102 (2007) 023504(1-6).

DOI: $10.1063 / 1.2753690$

[36] B.N. Samson, P.A. Tick, and N.F. Borrelli, Efficient neodymium-doped glass-ceramic fiber laser and amplifier, Optics Lett. 26 (2001) 145-147.

DOI: $10.1364 /$ OL.26.000145

[37] M. V. Dmitruk and A. A. Kaminskii, Stimulated emission from $\mathrm{LaF}^{3}-\mathrm{Nd}^{3+}$ crystal Lasers, Soviet Physics JETP 26(3) (1968) 531-534.

[38] H. H. Caspers, H. E. Rast, and R. A. Buchanan, Intermediate coupling energy levels for $\mathrm{Nd}^{3+}\left({ }^{4} \mathrm{f}_{3}\right)$ in $\mathrm{LaF}_{3}$, J. Chem. Phys. 42 (1965) 3214-3217.

DOI: $10.1063 / 1.1696401$

[39] J.Q. Hong, L. H. Zhang, P. X. Zhang, Y. Q. Wang and Y. Hang, Growth, optical characterization and evaluation of laser properties of $\mathrm{Nd}: \mathrm{LaF}_{3}$ crystal, J. Alloy Compd. 646 (2015) 706-709.

DOI: $10.1016 /$ j.jallcom.2015.05.172

[40] T. Ozawa, Kinetic analysis of derivative curves in thermal analysis, J. Thermal. Anal. 2 (1970) 301-324.

DOI: $10.1007 / \mathrm{BF} 01911411$

[41] K. Matusita and S. Sakka, Kinetic study of crystallization of glass by differential thermal analysis criterion on application of Kissinger plot, J. Non- Cryst. Solids 38-39 (1980) 41-746.

DOI: $10.1016 / 0022-3093(80) 90525-6$

[42] H.E. Kissinger, Variation of peak temperature with heating rate in differential thermal analysis, J. Res. Nat. Bur. Stand. 57 (1956) 217-221.

DOI: 10.6028 /jres.057.026

[43] B.D. Cullity, Elements of X-ray Diffraction, Addison-Wesley, Massachusetts, 1978.

[44] J. Ilavsky and P. R. Jemian, Irena: tool suite for modeling and analysis of small-angle scattering, J. Appl. Cryst. 42 (2009) 347-353.

DOI: $10.1107 /$ S0021889809002222

[45] M. Sroda, Effect of $\mathrm{Er}_{2} \mathrm{O}_{3}$ on thermal stability of oxyfluoride glass, J. Therm Anal Calorim. 97 (2009) 239-243.

DOI: $10.1007 / \mathrm{s} 10973-009-0257-3$

[46] I.W. Donald, Crystallisation kinetics of a lithium zinc silicate glass studied by DTA and DSC, J. Non- Cryst. Solids, 345-346 (2004) 120-126.

DOI: $10.1016 /$ j.jnoncrysol.2004.08.007 
[47] Z. Hu, Y. Wang, F. Bao and W. Luo,

Crystallization behavior and microstructure investigations on $\mathrm{LaF}_{3}$ containing oxyfluoride glass ceramics, J. Non-Crystal. Solids 351 (2005) 722-728.

DOI: $10.1016 /$ j.jnoncrysol.2005.01.075

[48] A. de Pablos-Martín, F. Muñoz, G.C. Mather, C. Patzig, S. Bhattacharyya, J.R. Jinschek, T. Höche, A. Durán and M.J. Pascual, $\mathrm{KLaF}_{4}$ nanocrystallisation in oxyfluoride glass-ceramics, Cryst. Eng. Comm. 15 (2013) 10323-10332.

DOI: $10.1039 / \mathrm{C} 3 \mathrm{CE} 41345 \mathrm{D}$

[49] P. Karmakar, A.K. Subudhi, K. Biswas and K. Annapurna, Crystallization kinetics analysis of $\mathrm{BaF}_{2}$ and $\mathrm{BaGdF}_{5}$ nanocrystals precipitated from oxyfluoride glass systems: a comparative study, Thermochim. Acta 610 (2015) 1-9.

DOI: $10.1016 / j$.tca.2015.04.019

[50] A.C Yanes, J. Del-Castillo, J. Méndez-Ramos, V.D. Rodríguez, M.E. Torres and J. Arbiol, Luminescence and structural characterization of transparent nanostructured $\mathrm{Eu}^{3+}$ doped $\mathrm{LaF}_{3}-\mathrm{SiO}_{2}$ glass-ceramics prepared by sol-gel method, Opt. Mater. 29 (2007) 9991003.

DOI: $10.1016 /$ j.optmat.2006.02.021

[51] N. Zhao, Wei Nie, Jun Mao, M. Yang, D. Wang, Y. Lin, Y. Fan, Z. Zhao, H. Wei and $\mathrm{X}$. Ji, A general synthesis of high-quality inorganic nanocrystals via a two-phase method, Small 6(22) $20102558-2565$.

DOI: $10.1002 / \mathrm{smll} .201001218$

[52] F. Li, C. Li, X. Liu, T. Bai, W. Dong, X. Zhang, Z. Shi and S. Feng, Microwaveassisted synthesis and up-down conversion luminescent properties of multicolor hydrophilic $\mathrm{LaF}_{3}: \mathrm{Ln}^{3+}$ nanocrystals, Dalton Trans. 42 (2013) 2015-2022.

DOI: $10.1039 / \mathrm{C} 2 \mathrm{DT} 32295 \mathrm{~A}$

[53] B.R. Judd, Optical absorption intensities of rare-earth ions, Phys. Rev. 127 (1962) 750761

DOI: $10.1103 /$ PhysRev.127.750

[54] G.S. Ofelt, Intensities of crystal spectra of rare-earth Ions, J. Chem. Phys. 37 (1962) 511-520.

DOI: $10.1063 / 1.1701366$

[55] W.T. Carnall, H. Crosswhite and H.M. Crosswhite, Energy level structure and transition probabilities of the trivalent lanthanides in $\mathrm{LaF}_{3}$, Argonne National Laboratory, Argonne, IL, 1977.

[56] S.F. Mason, R.D. Peacock, and B. Stewart, Ligand-polarization contributions to the intensity of hypersensitive trivalent lanthanide transitions, Mol. Phys. 30 (1975) 18291841.

DOI: $10.1080 / 00268977500103321$

[57] P. Nachimuthu and R. Jagannathan, Judd-Ofelt parameters, hypersensitivity, and emission characteristics of $\mathrm{Ln}^{3+}\left(\mathrm{Nd}^{3+}, \mathrm{Ho}^{3+}\right.$, and $\left.\mathrm{Er}^{3+}\right)$ ions doped in $\mathrm{PbO}-\mathrm{PbF}_{2}$ glasses, $\mathrm{J}$. Am. Soc. 82(2) 1999 387-392.

DOI: $10.1111 / \mathrm{j} .1551-2916.1999 . t b 20074 . \mathrm{x}$

[58] W.F. Krupke,

Induced-emission cross sections in neodymium laser glasses, IEEE J. of Quantum Electron.

QE-10 (1974) 450-457.

DOI: 10.1109/JQE.1974.1068162 